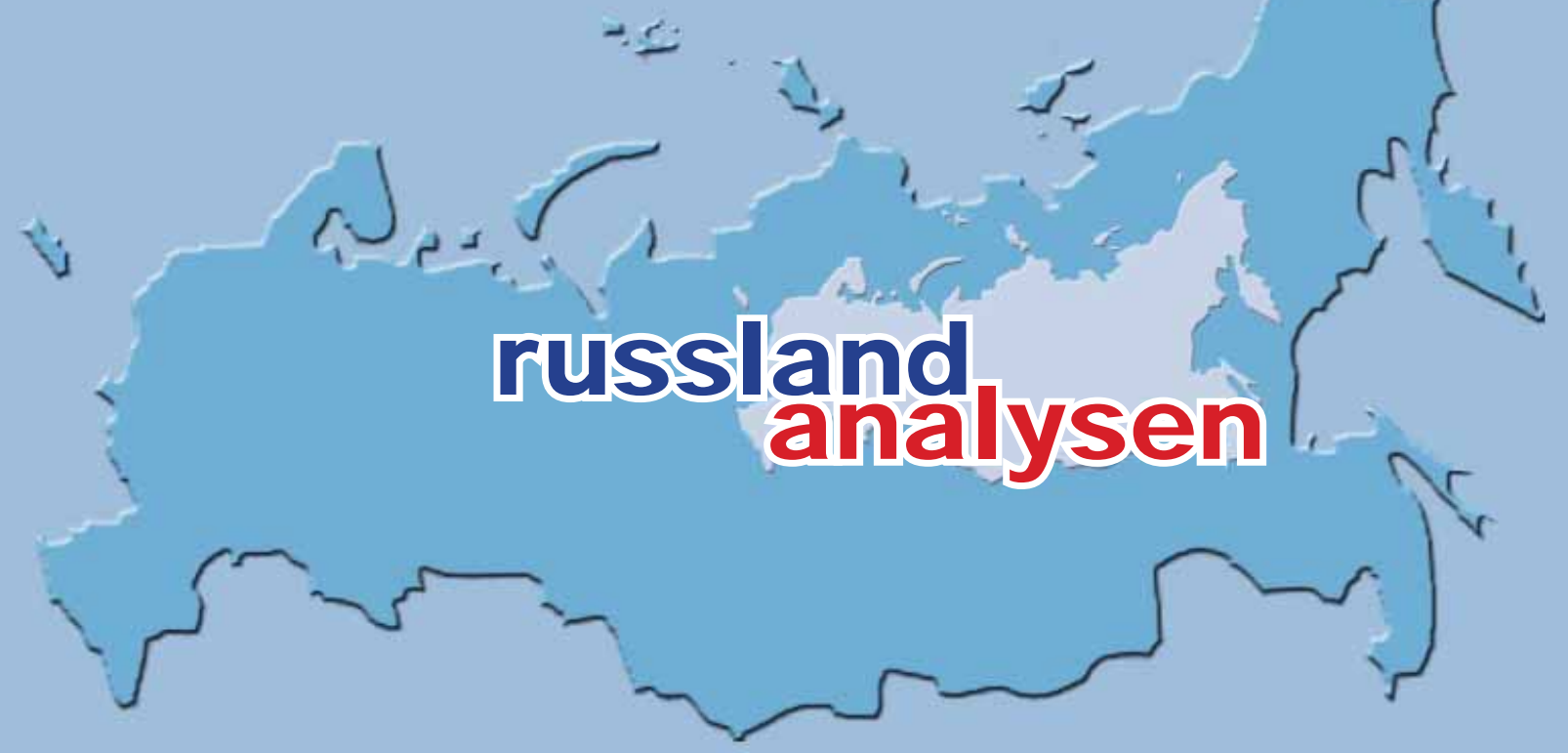

\title{
DER REGIERUNGSWECHSEL
}

ANALYSE

Auftakt zum Präsidentenwechsel? Überlegungen zur Regierungsumbildung in Russland 2

Von Henning Schröder, Bremen / Berlin

DOKUMENTATION

Biographien. Der neue Ministerpräsident und die neuen Minister

PRESSESTIMMEN

Der neue Ministerpräsident

Die neue Regierung

UMFRAGEN

Der Regierungswechsel

Die russischen Regierungen

Präsident Putin und die Nachfolgefrage

CHRONIK

Vom 12. bis zum 27. September 2007

\section{Aorschungsstelle Osteuropa}

Deutsche Gesellschaft für Osteuropakunde
Otto Wolff Stiftung 


\section{Analyse}

\section{Auftakt zum Präsidentenwechsel? Überlegungen zur Regierungsumbildung in Russland}

Von Henning Schröder, Bremen / Berlin

\section{Zusammenfassung}

Knapp drei Monate vor den Parlamentswahlen am 2. Dezember und sechs Monate vor den Präsidentenwahlen Anfang März 2008, stellt der russische Präsident Wladimir Putin die Führung des Landes neu auf. Der überraschende Schritt verrät zum einen etwas über das politische System und lässt zum anderen Rückschlüsse auf die Strategie zu, mit der die Präsidialverwaltung Putins Nachfolge inszenieren will.

Der Regierungswechsel zeigt, dass in Russland Wahlen für den Zugang zu politischer Macht nicht von Bedeutung sind. Politische Entscheidungen werden vielmehr in einem engen Kreis um den Präsidenten gefällt. Dies betrifft derzeit vor allem die Nachfolgefrage. Hier bietet sich mit Subkow eine neue Variante an: Der 66-jährige Agrar- und Finanzfachmann ohne politische Ambitionen wäre ein idealer Platzhalter für den zehn Jahr jüngeren Wladimir Putin. Unter der Ägide seines Vorgängers könnte Subkow vier Jahre als Präsident agieren, um dann wieder Putin Platz zu machen.

\section{Regierungswechsel im Vorfeld der Wahlen}

Am 12. September 2007 nahm Präsident Putin das Rücktrittsgesuch von Ministerpräsident Michail Fradkow an und nominierte Viktor Subkow, den pensionsreifen Chef der Finanzaufsicht, als dessen Nachfolger. Am 14. September bestätigte die Duma den Kandidaten des Präsidenten mit 381 gegen 47 Stimmen. Unmittelbar nach seiner Wahl machte sich der neue Ministerpräsident an die Neubildung der Regierung. (Siehe dazu die Biographien der neuen Minister und die Pressestimmen in den folgenden beiden Abschnitten.)

Knapp drei Monate vor den Parlamentswahlen am 2. Dezember und sechs Monate vor den Präsidentenwahlen Anfang März 2008, stellt der russische Präsident die Führung des Landes neu auf. Das ist erklärungsbedürftig - in der Bundesrepublik würde ein Kanzler seine Regierung 12 Wochen vor der Wahl sicher nicht aufösen. Der amerikanische Präsident George W. Bush, dessen Amtszeit ein halbes Jahr später endet als die Putins, wird von vielen Beobachtern schon jetzt als lame duck angesehen. Der russische Präsident hingegen ist durch die Spekulationen um seine Nachfolge keineswegs geschwächt - seine Autorität im Innern wie in der auswärtigen Politik ist unbestritten.

\section{Eine postsowjetische Tradition?}

In der neueren Geschichte Russlands ist ein solcher Schritt - ein Regierungswechsel kurz vor der Wahl allerdings nicht ungewöhnlich. Im Mai 1999 hatte »die Familie«, wie die Machtgruppe um den damaligen Präsidenten Boris Jelzin genannt wurde, den ungeliebten Ministerpräsidenten Jewgenij Primakow entlassen und an seine Stelle Innenminister Sergej Stepaschin gesetzt.
Als dieser nur bedingt erfolgreich war, wechselte man ihn Anfang August - vier Monate vor den Dumawahlen - gegen Putin aus, damals Chef des Inlandsgeheimdienstes FSB. Durch einen populistischen Kurs, der sich u.a. im militärischen Vorgehen gegen Tschetschenien ausdrückte, und durch eine massive Medienkampagne verschaffte "die Familie« Putin die große Popularität, die nötig war, um ihn Anfang 2000 als Nachfolger Jelzins zu installieren. Der 1999 vorgenommene Regierungswechsel war erkennbar Teil einer Strategie, die eine Person zum Präsidenten machen sollte, der »die Familie« vertrauen konnte.

Vier Jahre später löste Putin Ministerpräsident Michail Kasjanow im Februar 2004 - drei Wochen vor den Präsidentenwahlen - $a b$ und ersetzte ihn durch den weithin unbekannten Michail Fradkow, der als "technischer Premier « agierte, ohne erkennbare politische Ambitionen. Putin argumentierte, die Wähler sollten wissen, wie sich Politik in Zukunft gestalten würde und nicht durch einen Regierungswechsel nach der Wahl überrascht werden. Beobachter interpretierten den Schritt seinerzeit als Versuch, die Wähler für den Urnengang zu mobilisieren. Man befürchtete offenbar, dass viele Bürger zu Hause bleiben würden, da die Wiederwahl Putins ohnehin allgemein als ausgemachte Sache galt.

Wenn Präsident Putin nun, im Vorfeld von Parlaments- und Präsidentenwahlen, wiederum den Ministerpräsidenten auswechselt, so muss dies als wohlüberlegter politischer Kunstgriff verstanden werden. Ein Kunstgriff, der etwas über das politische System und den Charakter von Wahlen aussagt, und der etwas über die Strategie verrät, mit der die Putin-Administration Putins Nachfolge inszenieren will. 


\section{Wahlen - ohne Einfluss auf die Machtverhältnisse}

Wahlen sind ein zentrales Element von Demokratie. Durch Wahlen wird im politischen Wettbewerb geregelt, welche Gruppe für eine begrenzte Zeit die Entscheidungsgewalt innehaben soll. Zugleich verschaffen Wahlen der jeweiligen politischen Führung auch die notwendige Legitimation, Macht auszuüben. Insofern ist es die Regel, dass die Regierungsbildung den Wahlen folgt. Erst nach der Entscheidung des Souveräns der Wählerschaft - ist klar, wer in der nächsten Legislaturperiode Macht ausüben wird.

In der Russischen Föderation verhalten sich die Dinge etwas anders - sowohl rechtlich als auch praktisch. Die Regierung ist nicht dem Parlament, der Duma, verantwortlich, sondern dem Präsidenten, der auch die Minister ernennt. Nur im Falle des Ministerpräsidenten muss die Entscheidung des Präsidenten durch die Duma bestätigt werden. Die Auflösung der Regierung ist Sache des Präsidenten, das Parlament hat damit nichts zu tun. Bei Neuwahl des Präsidenten legt die Regierung ihre Vollmachten nieder - durch Dumawahlen wird ihre Tätigkeit nicht berührt. Bereits in der Verfassung ist also die Konzentration der politischen Macht in den Händen des Präsidenten angelegt - und damit auch die Schwäche des Parlaments.

Daher entscheiden die Dumawahlen auch nicht unmittelbar über die Machtverteilung. Die wirkliche Entscheidung fällt bei der Wahl des Präsidenten, der von der Bevölkerung direkt gewählt wird und so eine starke Legitimation erhält. Die Jelzin-Administration hat durchweg gegen eine Parlamentsmehrheit regiert und sich nur von Fall zu Fall Mehrheiten verschafft. Auch die Putin-Administration konnte sich zu Beginn der ersten Amtszeit 2000/01 nur bedingt auf die Duma verlassen, in der die kommunistische Opposition nach den Wahlen mit 20\% der Abgeordneten die stärkste Fraktion stellte. Der Präsident ist auf das Parlament nicht angewiesen, um so mehr als er allein über die bewaffnete Macht verfügt. Die so genannten »Machtminister « - der Verteidigungsminister, der Innenminister, der Katastrophenschutzminister und die Chefs der Dienste - ressortieren ebenso wie der Außenminister direkt beim Präsidenten. De facto hatten die Dumawahlen 1993 und 1995 keine wirkliche Bedeutung. Selbst wenn das Wahlvolk seine Opposition gegen Jelzin zum Ausdruck brachte, hatte dies kaum Einfluss auf politische Entscheidungen.

\section{Dumawahlen als Testlauf}

Im Jahre 1999 veränderte sich die Situation geringfügig. Bei den Präsidentenwahlen im Jahre 2000 musste ein Nachfolger für Jelzin gefunden werden, da dieser selbst laut Verfassung nicht für eine dritte Amtszeit kandidieren durfte. Die Dumawahlen im Dezember 1999 wurden zum Probelauf. Als sich zeigte, dass die im September 1999 von »der Familie« neu gegründete Partei "Einheit« im ersten Anlauf über 23\% der Wählerstimmen holte, und hinter der KPRF an zweiter Stelle lag, zog die Jelzin-Administration die Präsidentenwahlen in den März vor und lancierte ihren Kandidaten, Ministerpräsidenten Putin, indem sie ihn an Stelle von Jelzin zum amtierenden Präsidenten machte. Mögliche politische Konkurrenten wie der frühere Ministerpräsident Jewgenij Primakow oder der Moskauer Bürgermeister Jurij Lushkow verzichteten daraufhin auf eine eigene Kandidatur. Putins Wahl war gesichert.

Auch vier Jahre später waren die Dumawahlen im Dezember 2003 de facto eine Vorentscheidung. Nachdem die von der Präsidialverwaltung geförderte Partei "Einiges Russland" nach einer ebenso fulminanten wie skrupellosen Wahlkampagne in der Duma eine Zweidrittelmehrheit erreicht hatte, trat bei den Präsidentenwahlen kein ernstzunehmender Politiker mehr gegen Putin an. Einer der Konkurrenten, Sergej Mironow, heute Vorsitzender der Partei "Gerechtes Russland", trieb seine Loyalität so weit, dass er erklärte, er kandidiere zwar, setze sich aber tatsächlich für den Sieg Putins ein.

Die Präsidentenwahlen waren zur Farce geworden, die Parlamentswahlen zum Testlauf. Nach wie vor entschied die Zusammensetzung der Duma nicht über politische Macht, doch die Dumawahlen wurden zum Stimmungsbarometer, an dem die Machtelite ablas, wieweit das Regime in der Gesellschaft akzeptiert wurde. Wahlen sind in Russland kein Instrument des politischen Wettbewerbs, der Wahlakt verschafft dem Regime dennoch Legitimation. Daher ist die politische Führung an einer ordnungsgemäßen Durchführung und einer hohen Wahlbeteiligung interessiert.

\section{Politik als Elitenkonkurrenz}

Es sagt etwas über ein politisches System aus, wenn Wahlen nicht über den Zugang zur Macht entscheiden, wenn politischer Wettbewerb nicht öffentlich stattfindet. Selbst wenn der Wahlvorgang formal korrekt durchgeführt wird, dokumentiert er nicht den Willen des Souveräns - des Wahlvolkes -, und das System kann kaum als demokratisch bezeichnet werden.

Dennoch findet ein politischer Wettbewerb statt aber in einem engen Zirkel, jenseits der Öffentlichkeit. In der Tat hat sich die gesellschaftliche Kräftekonstellation seit der Endphase des Sowjetsystems nur unwesentlich geändert. In den zwanzig Jahren seit Beginn der Perestrojka im Januar 1987 hat sich die russische Gesellschaft nicht selbst organisiert, keine 
Interessen aggregiert und keine Gegenelite hervorgebracht. Gesellschaft war in der Ära Gorbatschow, wie in den Amtsjahren Jelzins und Putins durchweg nicht Träger, sondern Objekt von Politik. Entscheidungen wurden innerhalb einer zahlenmäßig kleinen Machtgruppe gefällt. Versuchte Gorbatschow noch gestützt auf Teile des ZK und des Parteiapparats die Sowjetunion zu modernisieren und das Regime zu liberalisieren, setzte die Jelzin-Administration gegen die Mehrheit der Bevölkerung die Liberalisierung der Märkte und die Privatisierung des Produktivkapitals durch. Die Konfrontation mit dem Parlament - damals hieß es noch Oberster Sowjet - und seine gewaltsame Auflösung im Oktober 1993 war ein Resultat dieser Politik. Eine Allianz zwischen politischen Eliten und neuem Geld war der Kern des Jelzin-Regimes.

Putin, von der Jelzin-Familie mit Bedacht ausgewählt, rührte nicht an die gesellschaftlichen Kräfteverhältnisse. Nach wie vor verfügt ein Elitenkartell über Macht und Produktivkapital - ohne wirksame öffentliche Kontrolle. Die Spielräume der Gesellschaft indes wurden in den beiden Amtszeiten Putins immer weiter eingeengt. Als Kompensation organisierte die Präsidialadministration eine Reihe von Parteien, die relevante Wählergruppen auffangen sollten, und schuf mit der Gesellschaftskammer eine Institution, die mit mehr oder weniger großem Erfolg Zivilgesellschaft simuliert. Gesellschaft wurde - im Sinne der klassischen Formel, die Dietrich Geyer für die Zeit Katharinas II. geprägt hatte - wieder eine »staatliche Veranstaltung".

\section{Die Putin-Kohorte}

Verschoben hat sich in der Amtszeit Putins jedoch die Zusammensetzung der Machtelite. Die Jelzinsche Allianz aus Präsident, Gouverneuren und ,Oligarchen hatte schon 1997 im so genannten `Bankenkrieg`, bei dem die Finanzmagnaten über die Modalitäten der Privatisierung lukrativer Staatsbetriebe in Streit gerieten, erste Risse gezeigt. Bei der Frage, wer der Nachfolge Jelzins werden sollte, zeichnete sich eine Konfrontation zwischen »der Familie« und einem Bündnis um Lushkow und Primakow ab. Die erfolgreiche Einführung des Kandidaten Putin im Vorfeld der Dumawahlen 1999 veranlasste Lushkow und Primakow dann zum Rückzug. Der neu gewählte Präsident ging alsbald gegen die `Oligarchen`vor, drängte solche mit politischen Ambitionen wie Gusinskij und Beresowskij aus dem Land und ließ Chodorkowskij ins Gefängnis werfen. Angehörige »der Familie« wie Ministerpräsident Kasjanow und Woloschin, den Leiter der Präsidialverwaltung entfernte er nach und nach aus seiner Umgebung. Dafür platzierte er eine große Zahl von Vertrauten aus dem Geheimdienst und aus seiner Zeit in der Petersburger Stadtverwaltung in Schlüsselpositionen.

Die russische Öffentlichkeit nahm das zunächst als Kampf der `Moskauer gegen die `Petersburger` wahr. Bald begann man zwischen >Petersburger Juristen/ Liberalen und 'Petersburger Tschekisten (Geheimdienstlern) zu differenzieren. Und nach Verdrängung der >Moskauer unterschied man nur noch zwischen ,Liberalen` und 'Silowiki (Angehörigen von Militär und Geheimdiensten). Ob diese Gruppeneinteilung so zutrifft, mag dahingestellt bleiben - der Sozialwissenschaftler Alexander Ausan etwa plädiert dafür, die schematische Zuordnung nach Herkunft aufzugeben und die Machtelite stattdessen nach der Verbindung mit den großen Staatskonzernen (Gazprom, Rosneft, EES Rossii, Russische Eisenbahnen, Sberbank und Rüstungssektor) zu gruppieren. In der Tat ist die PutinKohorte eng mit der Wirtschaft verflochten, sie hat es verstanden, sich und ihren Verwandten im Lauf der beiden Amtszeiten lukrative Posten in den wichtigsten Großunternehmen zu sichern. In den Putin-Jahren fand eine rzweite Umverteilung statt, in der die Privatisierungsgewinner der Jelzin-Zeit Teile ihrer Beute an Angehörige der Putin-Administration verloren.

Diese Erfahrung macht die Frage der Nachfolge Putins so brisant. Eine der wichtigen Aufgaben des russischen Präsidenten ist die Moderation zwischen den Elitefraktionen. Nur wenn es gelingt, die Interessen der verschiedenen Gruppierungen auszubalancieren, kann die Geschlossenheit des Elitenkartells und damit die Stabilität des Regimes erhalten werden. Putin hat diese Aufgabe offenbar zu allgemeiner Zufriedenheit gelöst. Tritt im März 2008 an seine Stelle ein anderer Politiker, dann besteht die Gefahr, dass dieser seine eigene Klientel befriedigen muss und eine dritte Umverteilung in Gang setzt. Damit sind nicht nur die Erwerbungen der Putin-Kohorte in Gefahr, ein Elitenkonflikt könnte im Extremfall auch in die Gesellschaft überschlagen und ein >ukrainisches Szenario‘, eine Welle gesellschaftlicher Aktivität, auslösen. Keine der Elitengruppen hat daran ein Interesse und daher optieren viele ihrer Vertreter für eine (verfassungswidrige) dritte Amtszeit Putins. Diesen Vorschlag aber weist der Amtsinhaber selbst konsequent zurück.

\section{Subkow - Signal für eine Nachfolgeregelung?}

Die Frage nach Putins Nachfolger ist seit langem Gegenstand heftiger Spekulationen. Hoch gehandelte Kandidaten waren lange Zeit die beiden Ersten Stellvertretenden Ministerpräsidenten Sergej Ivanow und Dimitri Medwedjew, von denen der erste als Kandidat der silowiki galt, der zweite als Sprecher der 'Liberalen`. Aber 


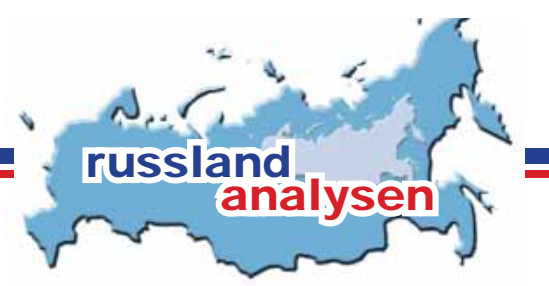

auch Wladimir Jakunin, der Chef des Russischen Bahnkonzerns, Sergej Naryschkin, ein weiterer Stellvertretenden Ministerpräsident oder Valentina Matwijenko, Gouverneurin von St. Petersburg, sind im Gespräch. Jetzt wird auch der neue Ministerpräsident Viktor Subkow zu den möglichen Kandidaten gezählt.

Der politische Wettbewerb zwischen den Kandidaten und den zugehörigen Elitefraktionen wird nicht bei den Wahlen ausgetragen. Diese Entscheidung wird vielmehr im Vorfeld »bei Hofe« ausgehandelt, im engeren Umkreis Wladimir Putins. Putin selbst hat sich bei der Frage seiner Nachfolge bedeckt gehalten, auch wenn diese Frage die gesamte zweite Amtszeit überschattet und die Eliten politisch gelähmt hat - in der Tat ist nach 2004 keine der vielen drängenden Reformen energisch vorangetrieben worden. Für Putin stellt sich aber die Frage nach seiner Rolle als Ex-Präsident. Die russische Verfassung ist so angelegt, dass die gesamte Macht beim Präsidenten konzentriert ist - für einen populären ExPräsident mit politischen Ambitionen ist da kein Platz. Jedem, der im März 2008 zum Präsidenten gewählt wird, muss daran gelegen sein, Putin möglichst rasch $\mathrm{zu}$ neutralisieren. Putin seinerseits wird nach seinen erfolgreichen Amtszeiten und dem hohen Vertrauensbonus, den er in der Gesellschaft genießt, nicht bereit sein, ohne weiteres in den Hintergrund zu treten.

Vor dem Hintergrund solcher Überlegungen erscheint Viktor Subkow beinahe als der ideale Nachfolger. Der 66-jährige Agrar- und Finanzfachmann ohne politische Ambitionen wäre der ideale Platzhalter für den zehn Jahr jüngeren Wladimir Putin. Unter der Ägide seines Vorgängers könnte Subkow vier Jahre als Präsident agieren, um dann wieder Putin Platz zu machen. Eine solches Szenario mit Subkow als Übergangslösung könnte sowohl die Elitenvertreter zufrieden stellen, die eigentlich eine dritte Amtszeit für Putin wünschen, als auch Putin selbst, der im Schlagschatten seines Nachfolgers weiter eine einflussreiche politische Rolle spielen könnte, während er sich als Nachfolger des Nachfolgers bereit hält.

Ob dieser Weg eingeschlagen wird, hängt sehr davon $\mathrm{ab}$, ob der neue Ministerpräsident von der Bevölkerung angenommen wird. Denn neben der Moderation von Elitenkonflikten hat der Präsidenten noch eine zweite Aufgabe, die für die Stabilität des Regimes von erheblicher Relevanz ist: er muss in der Gesellschaft für das Regime Akzeptanz schaffen. Das ist Putin in seinen beiden Amtszeiten hervorragend gelungen. Sein Image als bescheidener, anständiger, kluger, gesunder und um die kleinen Leute besorgter Staatsdiener hat ihm in der Bevölkerung ein hohes Vertrauensrating beschert. Die spin doctors der Präsidialadministration müssten nun Subkow in ähnlicher Weise als >Mann des Volkes aufbauen. Allerdings ist die Situation 2007/08 unvergleichlich schwieriger als 1999. Das Image Putins wurde als Gegenbild zu dem stammelnden, herzkranken Alkoholiker Jelzin entwickelt, dessen amigos Russland als Selbstbedienungsladen betrachteten. Subkow müsste jetzt gewissermaßen als ältere Putin-Version beworben werden. Wenn eine solche Kampagne bis zu den Dumawahlen keinen Erfolg zeitigt, dann muss allerdings wieder auf frühere Nachfolgevarianten zurückgegriffen werden: Ivanow, Medwedjew, Jakunin \& Co wären dann wieder im Spiel.

\section{Über den Autor}

Hans-Henning Schröder lehrt osteuropäische Geschichte an der Universität Bremen.

\section{Lesetipps}

Zur Lage des politischen Systems in Russland

- M. Buhbe; G. Gorzka (Hrsg.): Russland heute. Rezentralisierung des Staates unter Putin, Wiesbaden: VS Verlage für Sozialwissenschaften 2007.

- L. Gudkov: Rußlands Systemkrise. Negative Mobilisierung und kollektiver Zynismus, in: Osteuropa, 57.2007, Nr. 1, S. 3-13.

- M. Mommsen; A. Nußberger: Das System Putin. Gelenkte Demokratie und politische Justiz in Russland, München: Verlag C.H.Beck 2007 (= Beck'sche Reihe 1763).

- D. Furman: Ursprünge und Elemente imitierter Demokratien, in: Osteuropa, 56.2006, Nr. 9, S. 3-24.

- L.F. Ševcova: Garantiert ohne Garantie. Rußland unter Putin, in: Osteuropa, 56.2006, Nr. 3, S. 3-18. 


\section{Dokumentation}

\section{Biographien. Der neue Ministerpräsident und die neuen Minister}

\section{Viktor Subkow - ein Rentner als Ministerpräsident}

Viktor Alexejewitsch Subkow wurde am 15. September 1941 in der Siedlung Arbat (Gebiet Swerdlowsk) geboren. 1958-1960 arbeitete er als Schlosser in einem Reparaturbetrieb im Gebiet Murmansk und in einer Nickelgrube. 1960 nahm er das Studium an der Wirtschaftsfakultät des Leningrader Agrarinstituts auf, das er 1965 abschloss. Nach einem zweijährigen Wehrdienst fand er 1967 Anstellung in der Sowchos-Wirtschaft des Leningrader Gebiets, wo er bis 1985 Schritt für Schritt vom Leiter einer Abteilung der Sowchose »Krasnaja Slawjanka« bei Gatschina zum Generaldirektor des Sowchosenkonzerns »Perwomajskoe« aufstieg. 1985 wechselte Subkow aus dem Landwirtschaftsmanagement in die Partei- und Sowjetarbeit über. 1985-1986 war er Vorsitzender des Stadtexekutivkomitees (Bürgermeister) von Priosersk, einem Ort etwa 142 km von Leningrad entfernt. 1986-1987 - in der Anfangsphase der Perestrojka - fungierte er dort als Erster Sekretär des Stadtkomitees der KPdSU. 1987 stieg er im Parteiapparat auf und wurde Leiter der Abteilung Landwirtschaft und Nahrungsmittelindustrie im Leningrader Gebietskomitee der KPdSU. 1989 kehrte er aus dem Partei- in den Verwaltungsapparat zurück, nunmehr als Erster Stellvertretender Vorsitzender des Leningrader Gebietsexekutivkomitees.

Nach der Aufösung der Sowjetunion blieb Subkow in der Leningrader bzw. Petersburger Verwaltung. 1992-1993 hatte er die Position des Stellvertretenden Leiters des Komitees für Außenbeziehungen inne und war damit Stellvertreter Wladimir Putins. Aus dieser Zeit rührt Subkows Bekanntschaft mit dem russischen Präsidenten her. Es wird berichtet, es sei Subkow gewesen, der Putin in die Feinheiten der Kommunalverwaltung eingeführt habe.

1993 wechselte Subkow in die Finanzverwaltung und übernahm die Leitung der Steuerinspektion von St. Petersburg. Er überstand die Abwahl Sobtschaks 1995 und arbeitete unter dessen Nachfolger Anatolij Jakowlew weiter in den städtischen Finanzbehörden, zuletzt als deren Leiter. 1999-2001 stand er zugleich als Stellvertretender Finanzminister an der Spitze der Leningrader/Petersburger Territorialverwaltung des Ministeriums.

In dieser Zeit hielt Subkow weiter Kontakt zu Putin, der nach Moskau in die Präsidialverwaltung gewechselt war. Im Herbst kandidierte Subkow mit Putins Rückendeckung bei den Petersburger Gouverneurswahlen gegen Jakowlew, scheiterte jedoch. An der Spitze seines Wahlkampfstabes stand Boris Gryslow, später Putins Innenminister, heute einer der Führer der Partei »Einiges Russland» und Vorsitzender der Duma.

Kurz nach dieser Niederlage erwarb Subkow mit einer Promotion über "Die Vervollkommnung der Steuermechanismen des Mineral- und Rohstoffkomplexes am Beispiel des Gebiets Leningrad« den Rang eines »Kandidaten der Wissenschaften" (entspricht dem deutschen Doktortitel). Am 5. November 2001 ging er nach Moskau und wurde zum Stellvertretenden Finanzminister und Leiter des neu gebildeten Komitees für Finanzaufsicht ernannt. Im März 2004 wurde dieses Komitee in den »Föderalen Dienst für Finanzmonitoring (Rosfinmonitoring) beim Finanzministerium umgewandelt. Aufgabe dieser Behörde ist die Bekämpfung von Geldwäsche. Manche russischen Kommentatoren weisen darauf hin, dass deren Leiter in einer idealen Position ist, um sich Einblick in die Geschäfte der Führungseliten zu verschaffen - ein Wissen, das sich gegebenenfalls wohl auch als Druckmittel verwenden lässt. Im März 2007 wurde Subkow Mitglied der neu gegründeten Interministeriellen Arbeitsgruppe zur Korruptionsbekämpfung, an deren Spitze der Präsidentengehilfe Viktor Ivanow stand, eines der führenden Mitglied der »silowiki« (der Geheimdienstler und Militärs) im Umfeld Putins. Der Arbeitsgruppe gehörten u.a. ein Stellvertretender Direktor des Inlandsgeheimdienstes FSB, ein Stellvertretender Generalstaatsanwalt, der Stellvertretenden Justizminister sowie Abgeordnete der Duma und des Föderationsrates an. Sein Arbeitsbereich brachte Subkow also in engen Kontakt mit den Spitzen der "Machtministerien« und den »silowiki«.

Da Subkow im September 2006 das 65. Lebensjahr erreicht hatte, wurde im März 2007 auch seine Ablösung als Chef des Finanzmonitoring diskutiert, doch es kam nicht zur Ernennung eines Nachfolgers. Am 12. September nominierte ihn Präsident Putin als Ministerpräsidenten.

Subkow gehört seit langem Putins inneren Kreis an. Er ist der einzige "Petersburger«, der älter als Putin ist. Man sagt ihm nach, er habe keine eigenen politischen Ambitionen. Subkow ist verheiratet und hat eine Tochter, die in erster Ehe mit dem Sohn des Parteisekretärs von Priosersk verheiratet war. Ihr zweiter Ehemann ist Verteidigungsminis- 
ter Anatolij Serdjukow. Serdjukow, der in St. Petersburg mit Subkow in den Finanzbehörden arbeitete, gilt heute seinerseits als ein Vertrauter von Igor Setschin, einem anderen führenden »silowik«.

\section{Elvira Nabiullina. Die neue Wirtschaftsministerin}

Elvira Nabiullina wurde am 29. Oktober 1963 in Ufa geboren. 1986 absolvierte sie ihr Studium an der Moskauer Lomonossow-Universität als Diplom-Ökonom und promovierte anschließend. Seit 1991 arbeitete sie als Beraterin beim Russischen Industriellen- und Unternehmerverband und wechselte 1994 ins Wirtschaftsministerium, wo sie stellvertretende Leiterin und 1996 dann Leiterin der Abteilung für Wirtschaftsreformen wurde. Im Mai 1997 wurde sie zur stellvertretenden Wirtschaftsministerin ernannt. Nach der Finanzkrise 1998 schied sie aus dem Staatsdienst aus und arbeitete zuerst bei der »Promtorgbank« und dann beim Eurasischen Ratingdienst. 1999 wurde sie stellvertretende Präsidentin der Stiftung "Zentrum für strategische Entwicklungen«, die zusammen mit dem Wirtschaftsministerium Reformkonzepte entwerfen sollte.

Im Juni 2000 wurde Nabiullina zur ersten Stellvertreterin des Wirtschafts- und Handelsministers German Gref ernannt. Von 2003 bis 2005 war sie zusätzlich Präsidentin der Stiftung "Zentrum für strategische Entwicklungen«. Ab Oktober 2005 leitete sie den Expertenrat des Organisationskomitees für die Vorbereitung des russischen G8-Vorsitzes und eine Forschungsgruppe des »Zentrums für strategische Entwicklungen«. Am 24. September 2007 wurde Elvira Nabiullina zur Ministerin für Wirtschaftsentwicklung und Handel der Russischen Föderation ernannt und löst damit German Gref ab.

\section{Tatjana Golikowa. Die neue Sozialministerin}

Tatjana Golikowa wurde am 9. Februar 1966 in Mytischtschi (bei Moskau) geboren. Im Jahre 1987 schloss sie ihr Studium an der Moskauer Hochschule für Volkswirtschaft ab und arbeitete bis 1990 am Forschungsinstitut des Staatskomitees für Arbeit der UdSSR. Seit 1990 war sie im Finanzministerium der Russischen Föderation tätig: bis 1992 als Ökonomin der Abteilung für Haushaltspolitik, danach als Hauptökonomin und Leiterin der Abteilung für Haushaltspolitik. 1995 wurde Tatjana Golikowa zur stellvertretenden Leiterin und 1998 zur Leiterin der Haushaltsabteilung des Finanzministeriums ernannt.

Seit Juli 1999 arbeitete sie als stellvertretende Finanzministerin. Sie betreute Haushaltfragen, Fragen der Finanzierung der Sozialsphäre, der Wissenschaft und der Staatseinrichtungen. Am 24. September 2007 wurde Tatjana Golikowa vom Präsidenten Putin zur Ministerin für Gesundheit und Soziales ernannt und löste damit Michail Surabow ab, der für Probleme im Sozialbereich schon länger starker öffentlicher Kritik ausgesetzt war.

\section{Dmitrij Kosak. Der neue Regionalminister}

Dmitrij Kosak wurde am 7. November 1958 im Dorf Bondurowo (Kirowograder Gebiet) in der Ukraine geboren. 1985 beendete er sein Jurastudium an der Leningrader Universität und arbeitete anschließend als Staatsanwalt in der Staatsanwaltschaft Leningrads. Kosak gründete mehrere private Rechtsanwaltkanzleien, darunter »Newa Just«. Von 1989 bis 1990 war er Leiter der juristischen Abteilung des Konzerns »Monolit-Korovstroj«. 1990 wurde Kosak zum stellvertretenden Leiter und 1991 zum Leiter der Justizabteilung des Leningrader Exekutivkomitees ernannt. Von 1994 bis 1996 bekleidete er das Amt des Vorsitzenden des Justizkomitees der Petersburger Stadtverwaltung. Seit 1996 leitete Kosak die Justizabteilung der Gouverneursverwaltung Petersburgs. 1998 wurde er zum stellvertretenden Gouverneur Petersburgs befördert, schied jedoch im Dezember 1998 wegen Kontroversen mit Gouverneur Wladimir Jakowlew aus dem Amt aus und kehrte in die Firma »Newa Just« zurück, wo er als Rechtsanwalt arbeitete.

Im Mai 1999 wurde Kosak zum stellvertretenden Leiter des Präsidialamtes, im August 1999 zum ersten stellvertretenden Leiter des Regierungsapparates im Rang eines Ministers ernannt. Im Juni 2000 wurde er stellvertretender Leiter, dann erster stellvertretender Leiter des Präsidialamtes, zuständig für Verwaltungsreform, Gerichtsreform und Reform der örtlichen Selbstverwaltung. Seit dem 9. März 2004 leitete Dmitrij Kosak den Regierungsapparat der Russischen Föderation. Am 13. September 2004 wurde er bevollmächtigter Vertreter des Präsidenten im Südlichen Föderationsbezirk, gleichzeitig leitete er die föderale Sonderkommission für den Nordkaukasus. Kosak ist Mitglied des Sicherheitsrates der Russischen Föderation. Am 24. September 2007 wurde er vom Präsidenten Putin zum Minister für regionale Entwicklung ernannt und löste damit Wladimir Jakowlew ab. 


\title{
Alexej Kudrin. Beförderung zum stellvertretenden Ministerpräsidenten
}

Der am 12. Oktober 1960 in Dobele (Lettland) geborene Alexej Kudrin beendete 1983 sein Studium der Wirtschaftswissenschaften an der Leningrader Universität als Diplom-Ökonom. Nach dem Studium arbeitete er als wissenschaftlicher Mitarbeiter des Forschungsinstituts für soziale und wirtschaftliche Probleme der sowjetischen Akademie der Wissenschaften, wo er als Ökonom promovierte. Im Oktober 1990 wurde Kudrin zum stellvertretenden Vorsitzenden des Ausschusses für wirtschaftliche Reformen beim Leningrader Exekutivkomitee ernannt. Nachdem der Ausschuss aufgelöst worden war, wechselte er zur Stadtverwaltung Leningrads (seit 1991 Petersburg) und wurde 1991 stellvertretender Vorsitzender des Ausschusses für wirtschaftliche Entwicklung, 1992 Vorsitzender der Finanzverwaltung der Stadt, 1993 erster stellvertretender Oberbürgermeister Petersburgs.

1996 ging Kudrin nach Moskau, wo er vom damaligen Präsidenten Boris Jelzin zum stellvertretenden Leiter des Präsidialamtes ernannt wurde. Von 1997 bis 2000 (mit einigen Monaten Unterbrechung, in denen er als stellvertretender Vorstandschef des Energieversorgers "EES Rossii« arbeitete) war er als erster Stellvertreter des Finanzministers tätig. Am 9. März 2004 wurde Kudrin zum Finanzminister ernannt und am 24. September 2007 zusätzlich zum stellvertretenden Ministerpräsidenten befördert. Die russische Regierung hat damit fünf stellvertretende Ministerpräsidenten, unter denen die beiden ersten stellvertretenden Ministerpräsidenten Sergej Ivanow und Dmitrij Medwedjew eine hervorgehobene Position einnehmen.

Zusammengestellt von Hans-Henning Schröder (Subkow) und Olga Dudkowskaja

\section{Pressestimmen}

\section{Der neue Ministerpräsident}

\author{
Vedomosti (Moskau), 13.09.2007
}

\section{Ernennungen: Der »nicht-technische« Premier (Aleksej Makarkin)}

[...] Warum hat der Präsident Subkow gerade jetzt ernannt? Es lässt sich denken, dass sich die Konkurrenz in den Machtstrukturen um die Frage nach dem Nachfolger verschärft hat, dass man auf jeden Fall sehr schnell einige Entscheidungen bereits am Anfang der Wahlkampagne ins Parlament treffen musste. Die Verschärfung des Konkurrenzkampfes setzte die Stabilität der Machtstrukturen aufs Spiel, was in einer Situation, in der sie durch die »Wahlen ohne Putin« auf eine harte Probe gestellt würde, sehr ungünstig war. [...]

http:// w w w.vedomosti.ru/ new spaper/ article.shtml?2007/ 09/13/132630

\section{Komsomolskaja prawda (Moskau), 14.09.2007}

\section{Subkow ist für Putin eine Absicherung gegen Überraschungen (Andrej Baranow)}

Die plötzliche Ernennung von Viktor Subkow (der bis dahin im Land kaum bekannt war) zum Regierungschef gibt keinen Anlass, ihn für den Nachfolger zu halten, der im Frühjahr das höchste Amt im Kreml von W. Putin »erben« sollte. [...]

Gestern meinte Subkow, er schließe die Möglichkeit, um den Kreml zu kämpfen, nicht aus, falls er es schaffe, sich bis dahin als Regierungschef auszuzeichnen. Aber es scheint nur das nächste Ablenkungsmanöver zu sein.

Wahrscheinlicher ist es, dass er eine bescheidenere (aber sehr verantwortungsvolle) Aufgabe bekommen hat, die Regierungsreihen vom »Unkraut" - von den unpopulärsten Ministern - zu befreien. Ihre Namen sind allen bekannt. $[\ldots]$

http :// w w w.kp.ru/ daily/ $23967 / 73161$

\section{The Economist (London), 15.09.2007}

\section{Warum hat Russlands Präsident so einen unbekannten Premier ausgewählt?}

[...] Die unerwartete Ernennung von Subkow kann dreifach interpretiert werden. Zum ersten, dass Putin die Welt rätseln lassen möchte, ehe er einen der beiden Spitzenkandidaten fallen lässt. Zum zweiten, dass er einen völlig ande- 
ren Nachfolger im Auge hat - das kann Fradkow selbst sein (oder sogar noch überraschender - Subkow). Zum dritten, dass Putin noch nicht entschieden hat, wer es sein sollte. »Das ist keine Entscheidung, sondern ein Weg, die Entscheidung hinauszuzögern", schlussfolgert Julia Latynina, eine politische Kommentatorin.

Einige andere Analytiker schlagen eine vierte Möglichkeit vor, dass Putin eine Grundlage schaffen würde, um nach dem März 2008 im Amt zu bleiben. [...]

http:// w w w.economist.com/ wo rld/ europe/ displaystory.cfm? story_id =9803892\& C FID =14 422686\&C FT0 KEN =167 26009

Financial Times (London), 15.09.2007

\section{Putin hat einen "starken Mann" als Nachfolger im Visier (Stefan Wagstyl und Neil Buckley)}

Russlands Präsident Wladimir Putin sagte am Freitag, dass er möchte, dass sein Nachfolger ein starker Präsident wird - und fügte hinzu, dass Viktor Subkow, der wenig bekannte neue Premier, einer der fünf möglichen Nachfolger sei. $[\ldots]$

Putin sagte, Russland brauche einen starken Präsidenten, der seine eigene Leistungsfähigkeit und Unabhängigkeit gewährleisten könne, und fügte hinzu: »Ich habe kein Interesse an einem schwachen Präsidenten.« [...]

http:// w w w.ft.com/ cms/ s/ 0/ e7ee4 8 da-631f-11dc-b3ad-0 000779 fd2ac.html

Die Zeit (Hamburg), 12.09.2007

\section{Machtzynismus im Kreml (Johannes Voswinkel)}

[...] Die Regierungsumbildung ist der erste Schritt eines Geheimplans Putins zur Machtübergabe. Im Dezember steht die Parlamentswahl und im März nächsten Jahres die Neuwahl des Präsidenten an. Putin darf gemäß der Verfassung nicht mehr kandidieren. Die Einsetzung Subkows bedeutet keineswegs, dass er zum Kronprinzen Putins aufrückt. Sie bietet vor allem die Chance, sich von unpopulären Kabinettsmitgliedern wie dem Sozialminister oder dem liberalen und relativ freidenkerischen Wirtschaftsminister zu verabschieden. Sie haben als Sündenbock für die Versäumnisse der Landesführung ausgedient.

Das neue Vorwahlkabinett geht zur Erleichterung der Machtpartei »Einiges Russland « äußerlich reingewaschen und gestärkt in die Wahlkampagne. Subkow als neuer Premierminister könnte sich auch unter einem neuen Präsidenten an der Regierungsspitze halten - als von Putin eingesetztes Gegengewicht.

http :// w w w.zeit.de/ online/ $2007 / 37 /$ russland-regierung -ko mmentar

\section{FAZ (Frankfurt/Main), 17.09.2007}

\section{Putins Machtspiele (Michael Ludwig)}

[...] Putin geht es darum, dass auch nach dem Wechsel im Präsidentenamt die Ergebnisse und das Paradigma seiner Politik nicht nur nicht angezweifelt werden, sondern in Kraft bleiben. Die Ernennung Subkows fügt sich in dieses Bild. Subkow hat in sowjetischer Zeit Gehorsam gelernt. Mit dem Wissen, das er als oberster Finanzpolizist angesammelt hat, und dem daraus resultierende Drohpotential könnte er versuchen, mögliche Bestrebungen von Wirtschaftskreisen zur Beeinflussung der Politik abzublocken. In diesem Zusammenhang geht es auch darum, eine Revision der Verhältnisse im Rohstoffsektor zu verhindern. [...]

Ein wichtiger Teil der Strategie für den Wechsel an der Spitze, der die eigentlichen Machtverhältnisse freilich intakt lassen soll, besteht für Putin darin, möglichst lange die Zügel in der Hand zu behalten, zum geeigneten Zeitpunkt einen Nachfolger zu präsentieren und durchzusetzen. [...]

http:// w w w.faz.net/ s/ Rub7 FC 5BF30 C 45B402F96E964EF8C E790E1/ Doc E76E7EB9090D84DFBA 249A039A 7E A 8 E10 ATpl Ecommon Scontent.html

\section{Russia Morning Comment (United Financial Group, Moskau), 17.09.2007 Putin erklärt die Frage der Nachfolge 2008}

Letzten Freitag traf sich Präsident Putin mit westlichen Politologen und Journalisten in Sotschi. Er lieferte eine Reihe von Erklärungen, was noch mehr Spannung um die Nachfolgefrage von 2008 bedeutete. Er äußerte nämlich öffentlich 
seine Meinung über den neuen Premier Viktor Subkow, indem er ihn für seine Professionalität, Erfahrung und Ehrlichkeit lobte. Damit machte er klar, dass Subkow in der Lage sei, der nächste Präsident Russlands zu werden. [...]

Aber dann, als es schien, dass die Identität des Nachfolgers endgültig klar war, brachte Putin geschickt wieder Ungewissheit in das Präsidentschaftsrennen: Er sagte, dass fünf potentielle Kandidaten für die Präsidentschaft jetzt genannt werden könnten, und dass es für die russischen Wähler sogar besser sei, wenn sich der neue Premier als der schlechteste Kandidat herausstellen würde. [...] Das Szenario für das Präsidentschaftsrennen 2008 könnte völlig anders aussehen als früher erwartet. Anstatt dass ein Nachfolger einfach ernannt würde, könnte Russland ein Konkurrenzrennen zwischen mehreren potentiellen Kandidaten bekommen. Ein Konkurrenzszenario hat den Vorteil, dem Präsidentschaftsrennen einen demokratischeren Anschein zu geben, wobei Putins letzte Wahl erst ganz am Schluss enthüllt wird, vielleicht sogar bei den Stichwahlen.

Putins Äußerungen sind so konzipiert, dass sie ihm viel Freiraum für politische Manöver lassen. Egal, welche Informationen über das »Nachfolgeverfahren« in den letzten Tagen gegeben wurden, Putin bleibt der oberste Schiedsrichter im Hinblick auf den zukünftigen Kurs der Wahlkampagne.

\section{Die neue Regierung}

\section{Kommersant (Moskau), 25.09.2007}

\section{"Sie haben nicht richtig gesessen "(Dmitrij Butrin, Maksim Schischkin)}

Die Reformen im Weißen Haus wurden auf leise Umstrukturierungen beschränkt. Außer Michail Fradkow haben auch der Wirtschaftsminister German Gref, der Sozialminister Michail Surabow und der Regionalminister Wladimir Jakowlew ihre Ämter in Fradkows Kabinett verloren. Alle drei Entlassungen überraschen jedoch nicht. Alle drei Minister stellten bereits 2007 ihre Rücktrittsgesuche. Alle waren sie zum Gegenstand der öffentlichen Kritik geworden - in erster Linie durch Michail Fradkow. German Gref wurde das letzte Mal in der Regierungssitzung am 6. September für das Scheitern der Staatsinvestitionsprogramme kritisiert. Der Vortrag von Jakowlew über Strategien im Wohnungsbau wurde am 20. September von der Tagesordnung der Regierungssitzung aufgrund offensichtlicher Durchführungsprobleme genommen. Michail Surabow hatte die Probleme mit dem System der zusätzlichen Arzneimittelversorgung in den Jahren 2005-2007 zu verantworten. Sein Rücktritt wurde sowohl von den Parteien "Einheitliches Russland« und "Gerechtes Russland« als auch von der Bevölkerung, deren Abneigung gegen Surabow von den Lobbyisten der Parteien zusätzlich in den Massenmedia bekräftigt wurde, gefordert.

http:// w w w.kommersant.ru/ doc.aspx?DocsID =808009

\section{Vedomosti (Moskau), 25.09.2007}

\section{Drei Änderungen (Alexandra Petratschkowa, Anna Nikolaewa)}

[...] Die Staatsspitze hat sich nicht getraut, die Regierungsstruktur radikal zu verändern. [...] Der zweite und damit entscheidende Schritt in der Umstrukturierung des Kabinetts, der die innere Umbildung der Ministerien selbst betrifft, wird nach den Parlamentswahlen vorgenommen. [...]

"Im Kreml wurde über ernsthaftere Änderungen in der Regierungsstruktur nachgedacht, aber dort siegte der Standpunkt, die `Pferde`, wie bei einem Flussübergang, vor den Wahlen nicht zu wechseln«, vermutet der Politologe Vitalij Iwanow: »Einige hatten ihre Beschützer, für andere fand man einfach keinen Ersatz, wie für Sokolow, der ebenfalls aus der Regierung entlassen werden sollte«.

„Der Grund für eine zehntägige Pause bei der Verkündung der neuen Regierungszusammensetzung könnte der Kampf um Serdjukow (Schwiegersohn Subkows) gewesen sein«, stellt der Politologe Aleksej Makarkin fest, »dies bedeutet, dass Subkow stärker als Fradkow sein wird, denn der letzte hatte gar keine eigenen Minister in der Regierung«. $[\ldots]$

http:// w w w.vedomosti.ru/ new spaper/ article.shtml?2007/ 09/25/133275 
Neue Zürcher Zeitung (Zürich), 25.09.2007

\section{Putin stellt Russlands neue Regierung vor}

[...] Bis auf drei Minister setzt sich die Regierung Subkows damit aus denselben Personen wie unter Ministerpräsident Fradkow zusammen. Das ist umso erstaunlicher, als zahlreiche Äußerungen Putins und Subkows darauf hingedeutet hatten, dass sich an der Organisation der Ministerien und der personellen Zusammensetzung einiges ändern müsse. Die Befürchtung, dass die letzten Vertreter prononciert liberaler Wirtschaftspolitik wie Gref und Kudrin dem Wahlkampf geopfert werden könnten, war voreilig. Während Kudrin sogar befördert wurde, tritt mit Nabiullina eine profilierte liberale Wirtschaftsexpertin mit internationaler Vernetzung Grefs Nachfolge an. Ein Zückerchen für die Wähler ist die gleichzeitig bekanntgegebene Rentenerhöhung. Der Kurs im Land wird sich damit bis auf Nuancen nicht ändern. Die wichtigste Frage mit den spekulativsten Antworten - jene nach Putins Nachfolge - bleibt nach dem Revirement so offen wie nie.

http:// w w w.nzz.ch/ nachrichten/ international/ putin_stellt_russlands_neue_regierung_vor_1.560437.html

\section{Russia Morning Comment (United Financial Group, Moskau), 25.09.2007 Putin gibt die Zusammensetzung des neuen Kabinetts bekannt}

[...] Die wichtigsten Fragen in Bezug auf die Zusammensetzung des neuen Kabinetts betrafen das Schicksal der beiden Minister aus dem Wirtschaftsbereich, und zwar: des Finanzministers und des Ministers für Wirtschaftsentwicklung und Handel. Die Entlassung von German Gref aus dem Kabinett wurde erwartet. Seine Nachfolgerin, Elvira Nabiullina, hat früher als stellvertretende Ministerin für Wirtschaftsentwicklung und Handel gearbeitet und gilt als ein Mitglied des Teams von Gref, so dass sie die Fortführung der bisherigen Politik des Wirtschaftsministeriums, einschließlich solcher Fragen wie WTO-Beitritt und die Entwicklung von Infrastruktur, sichern kann. [...]

Dem Sozialbereich wird im Hinblick auf den Staatshaushalt vor den Wahlen 2007-2008 hohe Priorität zugemessen werden, und wir erwarten in dieser Hinsicht, dass der Markt sehr positiv auf die Ernennung von Tatjana Golikowa, der ehemaligen stellvertretenden Finanzministerin, reagiert. Golikowa gilt als diejenige, die sich mit der russischen Haushaltspolitik auskennt. Sie vertrat oft das Finanzministerium bei den Haushaltsdebatten in der Staatsduma. Dass die Verantwortung für den Sozialbereich einer der führenden Technokraten aus Kudrins Ministerium übertragen wurde, kann die Sorgen über die Nutzung von Staatsgelder zur Finanzierung der Sozialsphäre vor den Wahlen lindern.

Financial Times (London), 25.09.2007

\section{Reformer gewinnen die Regierungsumstrukturierung in Russland (Neil Buckley)}

[...] Bei einem Treffen mit der neuen Regierungsmannschaft forderte Putin sie auf, die Effektivität der Regierung zu erhöhen. Er sagte, die vorige Regierung sei durch die Parlamentswahlen im Dezember und die Präsidentschaftswahlen im März nächsten Jahres, wenn er nicht mehr kandidiert, von ihrer Tätigkeit abgelenkt worden. „Wir müssen nicht nur Stabilität gewährleisten, sondern auch die Realisierung unserer strategischen Pläne vorwärts bringen«, fügte er hinzu.

http:// w w w.ft.co m/ cms/ s/ 0/ e526 d95 e-6 aff-11dc-9410-00007 79 fd 2ac.html 


\section{Umfragen}

\section{Der Regierungswechsel in den Augen der russischen Bevölkerung}

\section{Erwartungen an den Regierungswechsel (2004 und 2007 im Vergleich)}

Was erwarten Sie vom Regierungswechsel?

\begin{tabular}{l|c|c|}
\hline Eine Verbesserung & $34 \%$ & $24 \%$ \\
\hline Eine Verschlechterung & $7 \%$ & $10 \%$ \\
\hline Keine Veränderung & $44 \%$ & $49 \%$ \\
\hline Keine Antwort & $15 \%$ & $16 \%$ \\
Löst die neue Regierung die Probleme Russlands effektiver als die vorige? & $38 \%$ & $32 \%$ \\
\hline Effektiver & $13 \%$ & $17 \%$ \\
\hline Weniger effektiv & $11 \%$ & $16 \%$ \\
\hline Anderes & $39 \%$ & $35 \%$ \\
\hline Keine Antwort & \multicolumn{2}{|c|}{} \\
\hline
\end{tabular}

Wird es in der neuen Regierung mehr oder weniger Bürokratie und Unordnung geben als in der alten?

\begin{tabular}{l|l|l} 
Mehr & $10 \%$ & $12 \%$ \\
Genauso viel & $50 \%$ & $58 \%$ \\
\hline Weniger & $24 \%$ & $14 \%$ \\
\hline Keine Antwort & $16 \%$ & $16 \%$
\end{tabular}

Wird es in der neuen Regierung mehr oder weniger Korruption geben als in der alten?

\begin{tabular}{l|c|c|}
\hline Mehr & $10 \%$ & $12 \%$ \\
\hline Genauso viel & $49 \%$ & $57 \%$ \\
\hline Weniger & $23 \%$ & $15 \%$ \\
\hline Keine Antwort & $17 \%$ & $16 \%$
\end{tabular}

Quelle: Umfragen des Lewada-Zentrums vom September 2007 http:/ / w w w.levada.ru./ press/ 2007092104 .html

Welche Minister der russischen Regierung würden Sie in die neue Regierung aufnehmen, und welche austauschen?

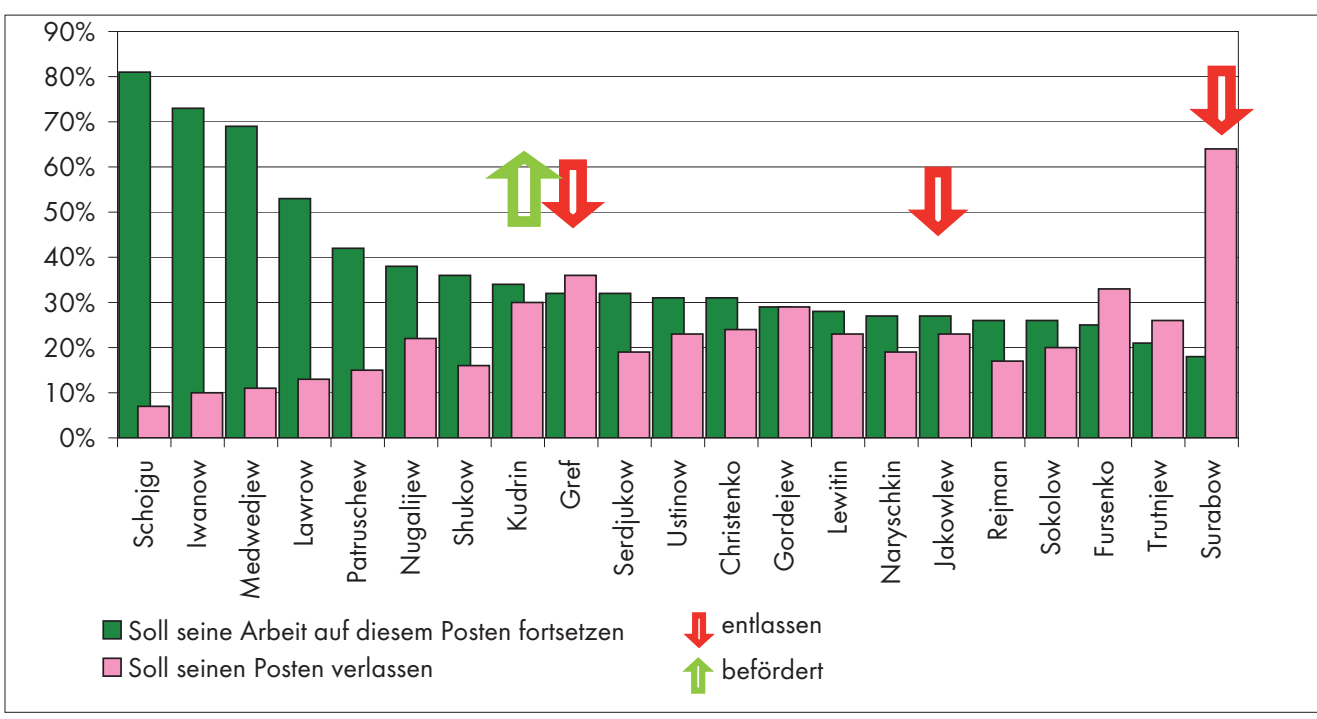

Nach: http:/ / wciom.ru/ novosti/ press-vypuski/ press-vypusk/ single/ $8880 \mathrm{html}$, 25.9.2007 
Die Perspektiven der neuen Regierung

Wie lange wird Subkow den Posten des Ministerpräsidenten innehaben?

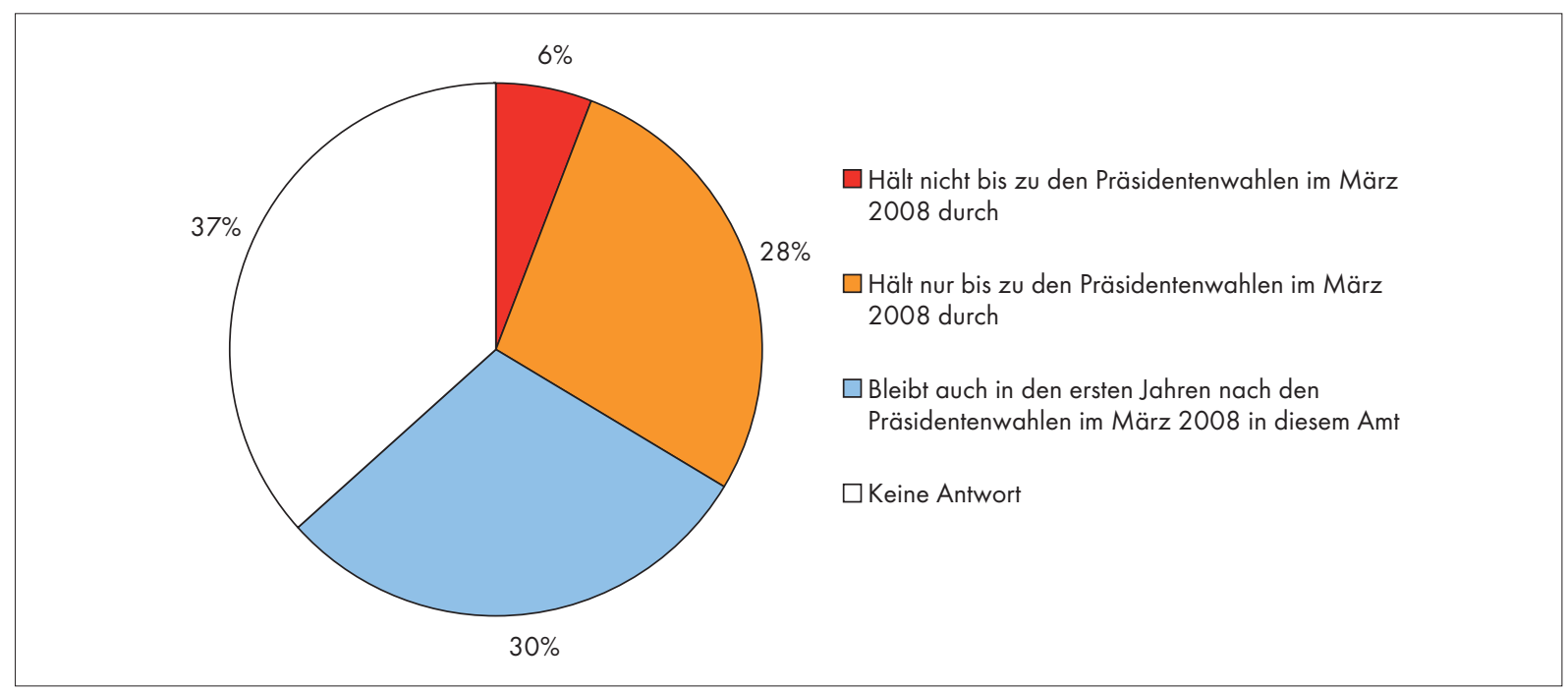

Bedeutet die Ernennung Subkows zum Ministerpräsidenten, dass er Nachfolger Putins als Präsident wird?

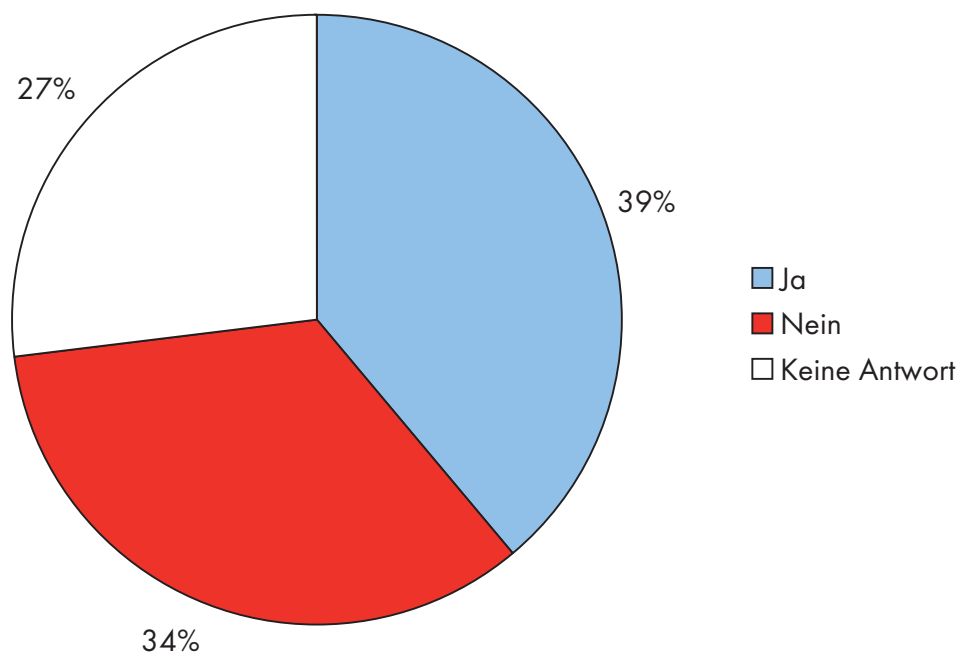

Quelle: Umfragen des Lewada-Zentrums vom September 2007 http:/ / w w w.levada .ru./ press/ 2007092101 .html 
Die russischen Regierungen in den Augen der russischen Bevölkerung

Wie bewerten Sie die Tätigkeit des russischen Ministerpräsidenten?

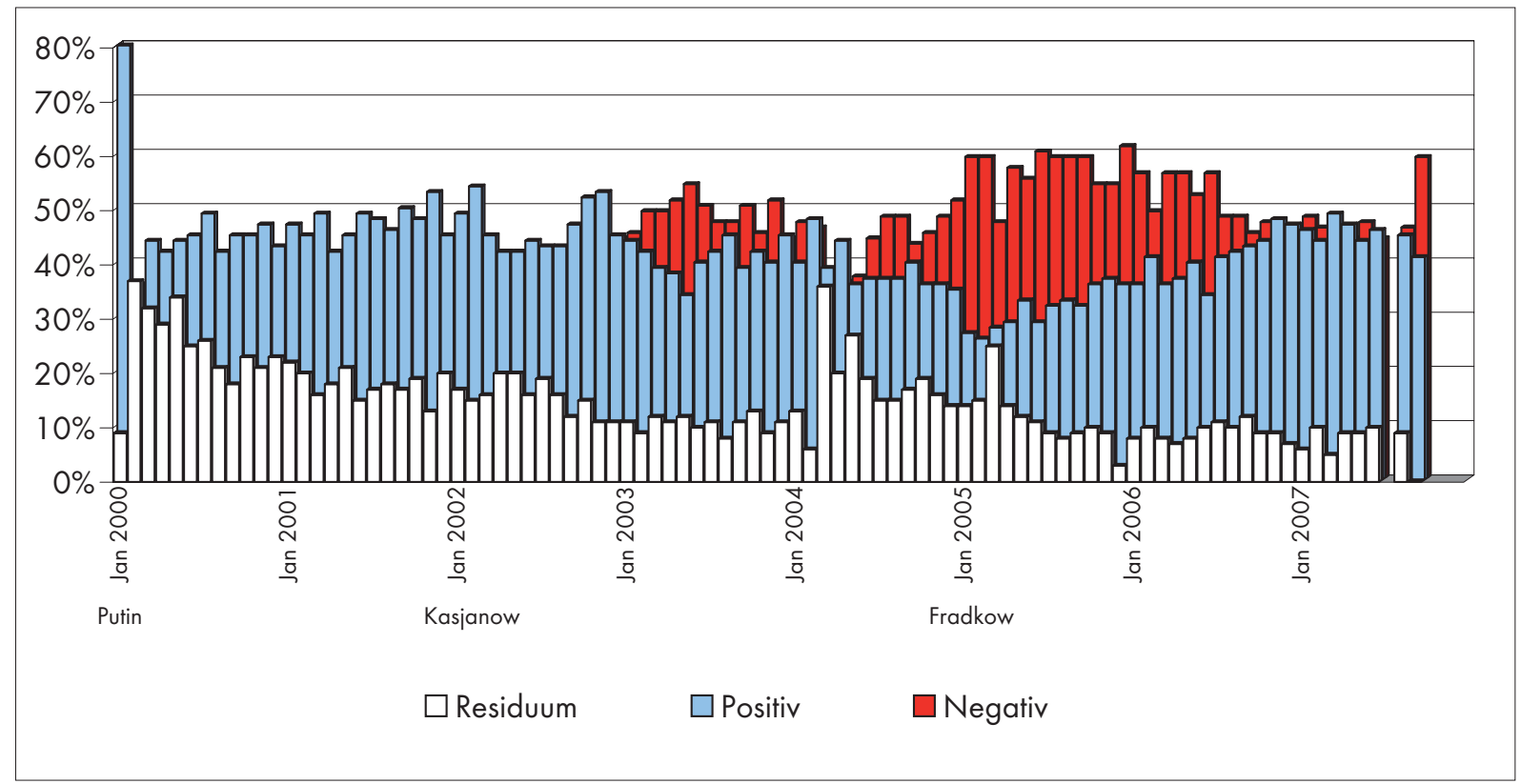

Wie bewerten Sie die Tätigkeit der russische Regierung?

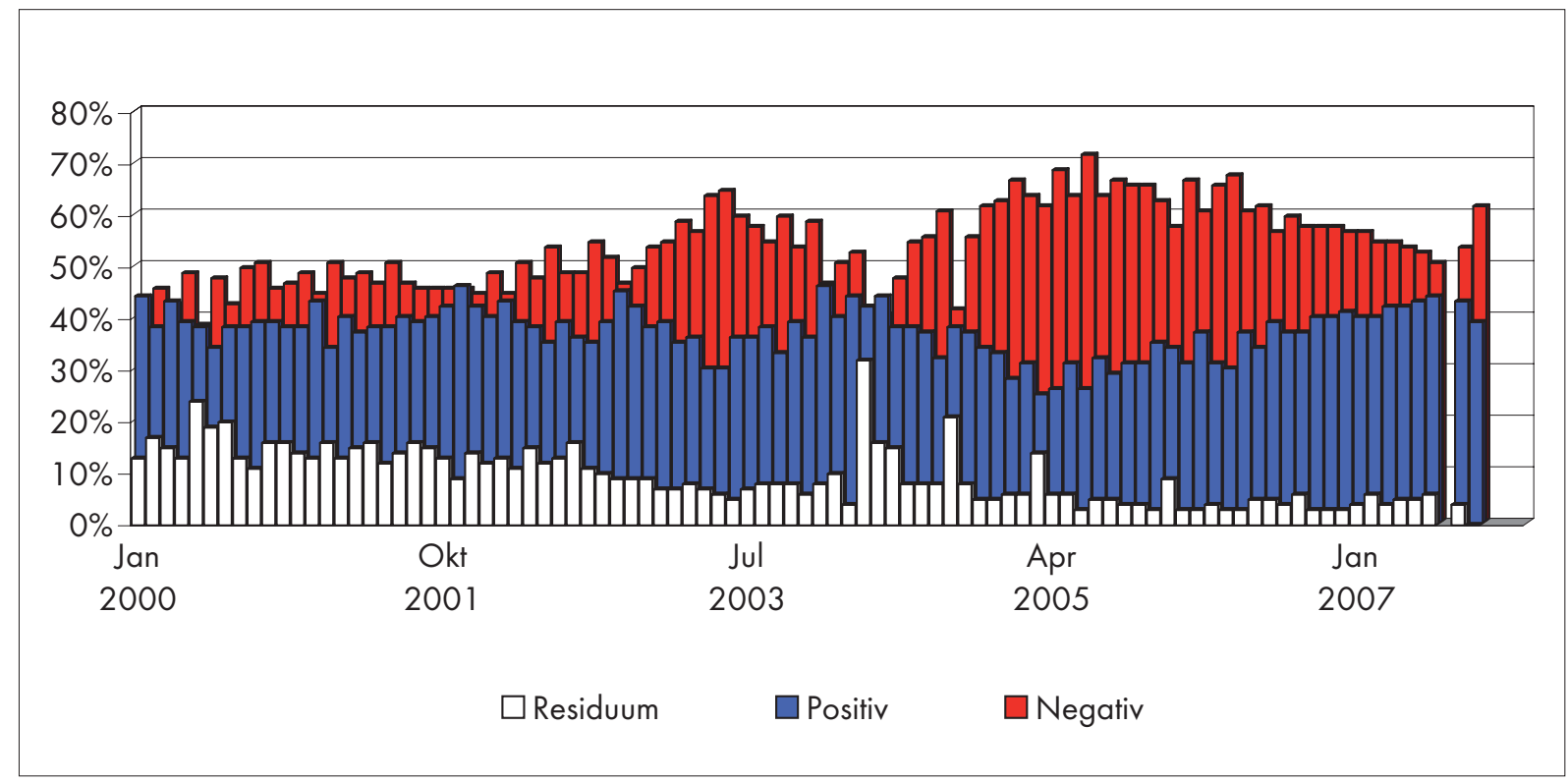

Quelle: Umfragen des Lewada-Zentrums http:/ / w w w.levada.ru./ pravitelstvo.html 
Was sind Ihre wesentlichen Kritikpunkte an der Regierung?

\begin{tabular}{|c|c|c|c|c|}
\hline & $\begin{array}{c}\text { Tschenomyr- } \\
\text { din (bis 1998) }\end{array}$ & $\begin{array}{c}\text { Kirijenko } \\
(1998)\end{array}$ & $\begin{array}{c}\text { Kasjanow } \\
(2000-2004)\end{array}$ & $\begin{array}{c}\text { Fradkow } \\
(2004-2007)\end{array}$ \\
\hline Kein durchdachtes Programm zur Überwindung der Krise & $25 \%$ & $19 \%$ & $15 \%$ & $17 \%$ \\
\hline Niedrige professionelle Kompetenz & - & - & $8 \%$ & $10 \%$ \\
\hline $\begin{array}{l}\text { Kann das Preiswachstum und den Fall der Einkünfte nicht } \\
\text { aufhalten }\end{array}$ & $34 \%$ & $27 \%$ & $30 \%$ & $34 \%$ \\
\hline $\begin{array}{l}\text { Kümmert sich nicht um den sozialen Schutz der Bevölke- } \\
\text { rung }\end{array}$ & $34 \%$ & $29 \%$ & $22 \%$ & $30 \%$ \\
\hline Kämpft nicht wirksam gegen Kriminalität & $13 \%$ & $14 \%$ & $12 \%$ & $12 \%$ \\
\hline $\begin{array}{l}\text { Kann die Sicherheit der Bürger nicht gewährleisten, den } \\
\text { Terrorismus überwinden }\end{array}$ & - & - & $12 \%$ & $9 \%$ \\
\hline Kann die Arbeitslosigkeit nicht überwinden & $16 \%$ & $17 \%$ & $15 \%$ & $18 \%$ \\
\hline Beschädigt die Wirtschaft, die Unternehmen & $17 \%$ & $12 \%$ & - & - \\
\hline $\begin{array}{l}\text { Kann die Wirtschaftskrise und den Produktionsrückgang } \\
\text { nicht überwinden }\end{array}$ & - & - & $16 \%$ & $17 \%$ \\
\hline Handelt im Interesse des Schattenkapitals, der Mafia & $13 \%$ & $9 \%$ & $9 \%$ & $6 \%$ \\
\hline Handelt im Interesse des ausländischen Kapitals & $7 \%$ & $8 \%$ & $4 \%$ & $4 \%$ \\
\hline Korrupt, handelt vor allem im eigenen Interesse & $17 \%$ & $10 \%$ & $15 \%$ & $19 \%$ \\
\hline Führt einen eigenartigen Krieg in Tschetschenien & - & - & $8 \%$ & - \\
\hline Anderes & $3 \%$ & $5 \%$ & $3 \%$ & $6 \%$ \\
\hline Keine Kritikpunkte & $11 \%$ & $13 \%$ & $19 \%$ & $20 \%$ \\
\hline Keine Antwort & $10 \%$ & $19 \%$ & $13 \%$ & $11 \%$ \\
\hline
\end{tabular}

Quelle: Umfragen des Lewada-Zentrums vom September 2007 http:/ / w w w.levada.ru./ press/ 2007092104 .html

Präsident Putin und die Nachfolgefrage in den Augen der russischen Bevölkerung

Wenn am Sonntag Präsidentenwahlen wären, für welchen Kandidaten würden Sie stimmen?

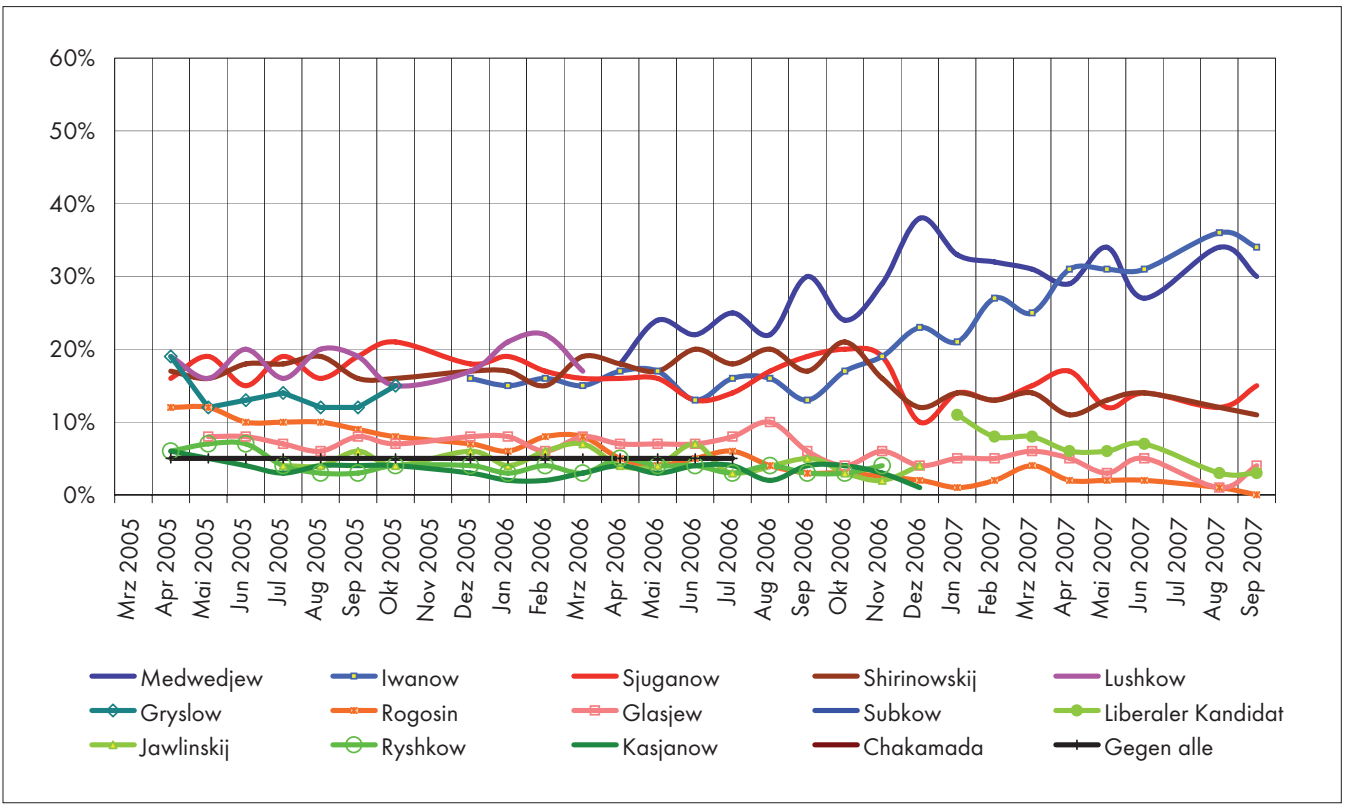


Werden Sie bei den kommenden Wahlen für Putins Kandidaten stimmen oder für einen anderen?

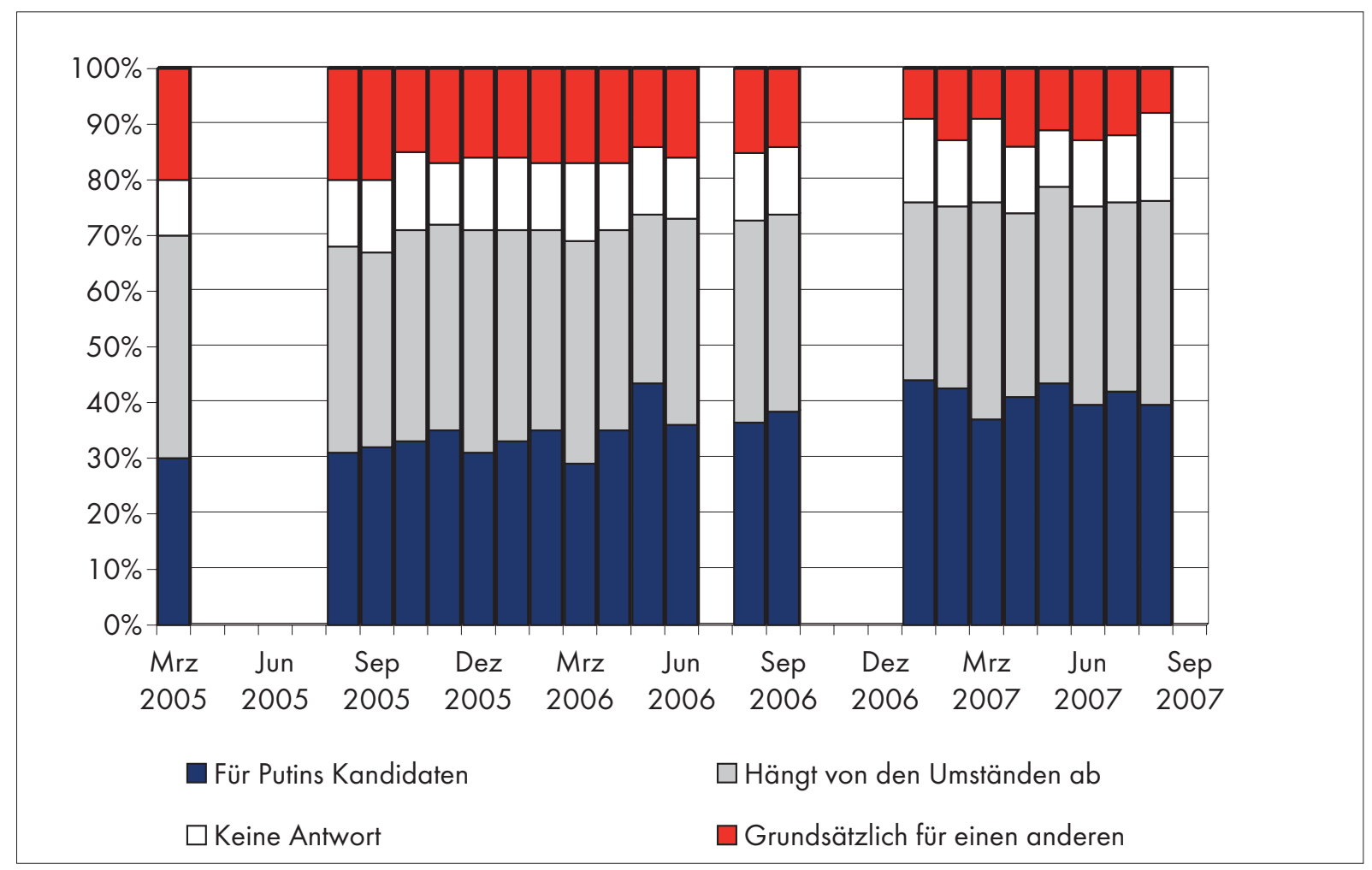

Nach: http:/ / ww w.levada.ru./ vybory2008.html, 23.9.2007

Bedeutet Putins Rückzug aus dem Amt des Präsidenten mehr Gutes oder mehr Schlechtes?

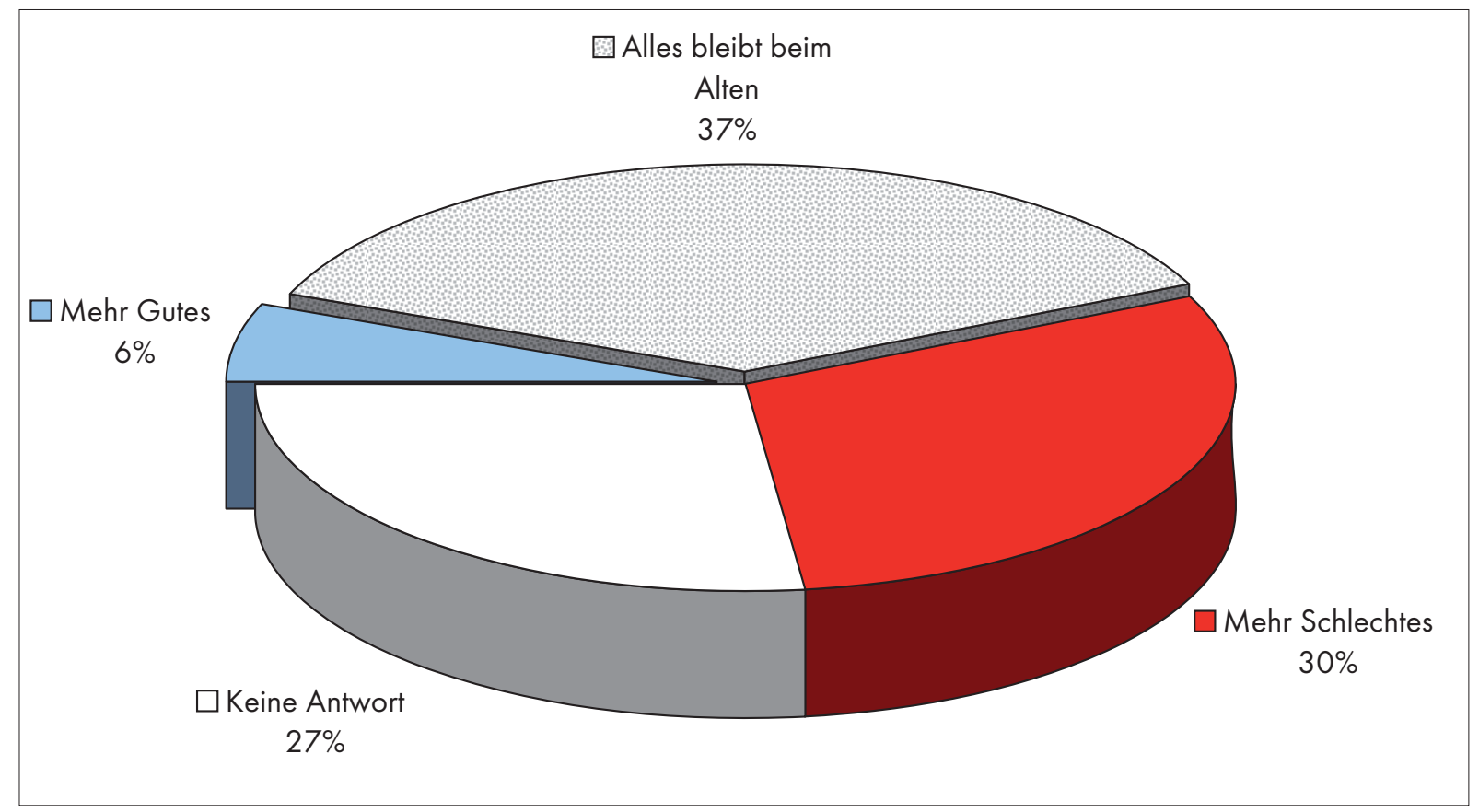

Quelle: Umfragen der "Stiftung Öffentliche Meinung", Juli/August 2007 http:/ / bd.fom.ru/ report/ map/ p rojects/ do minant/ do m0732/ domt0732 2/d07322 
Wie stehen Sie dazu, wenn Putin in der Politik bleibt und aktiv am politischen Leben des Landes teilnimmt?

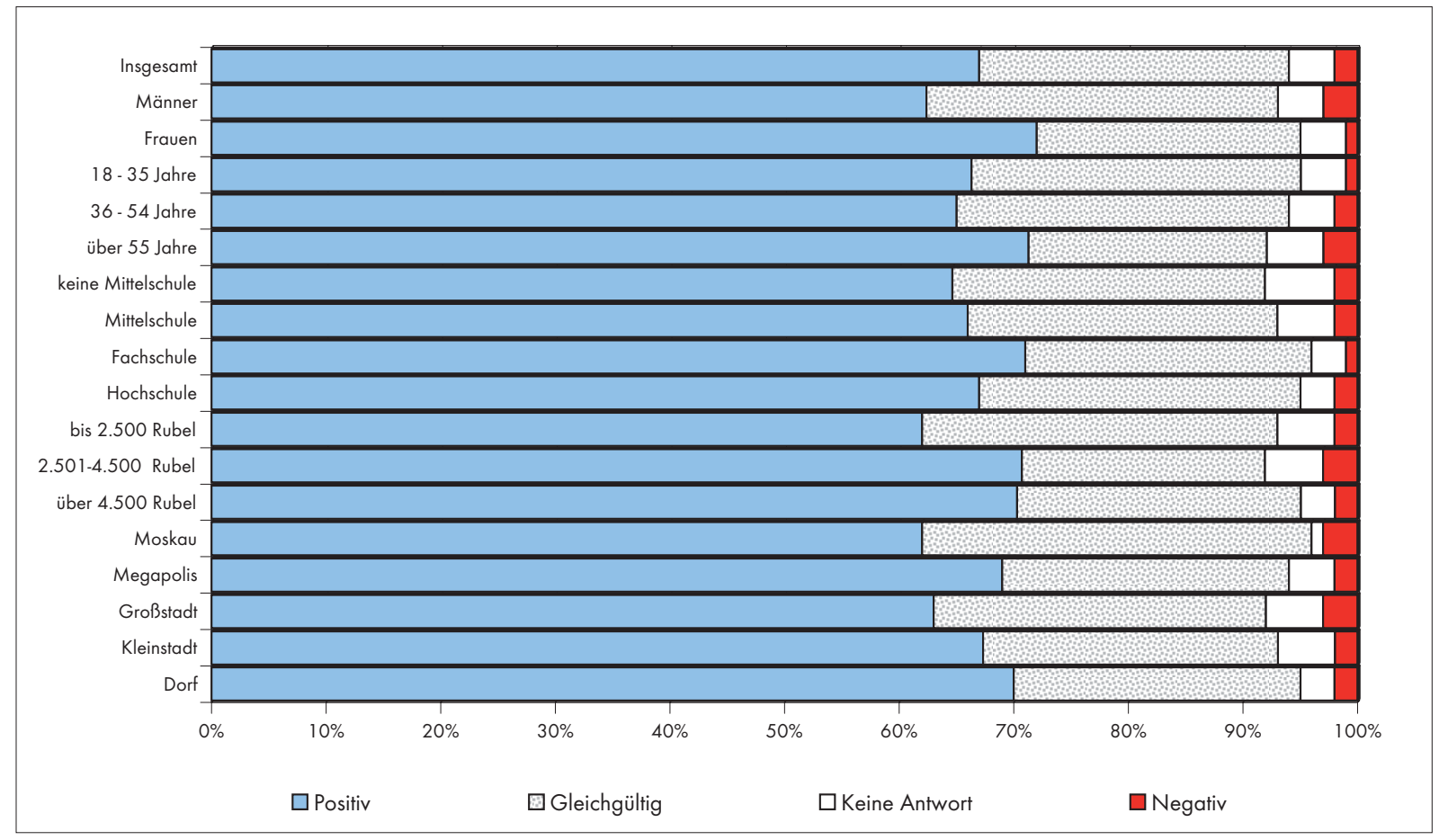

Quelle: Umfragen der "Stiftung Öffentliche Meinung", Juli/August 2007 http:/ / bd.fo m.ru/ report/ map/ p rojects/ do minant/ do m0732/ domt0732 2/d07322

Wessen Interessen vertritt Putin Ihrer Meinung nach? (Mehrfachnennungen möglich, alle Gruppen mit mehr als $10 \%$ Zustimmung)

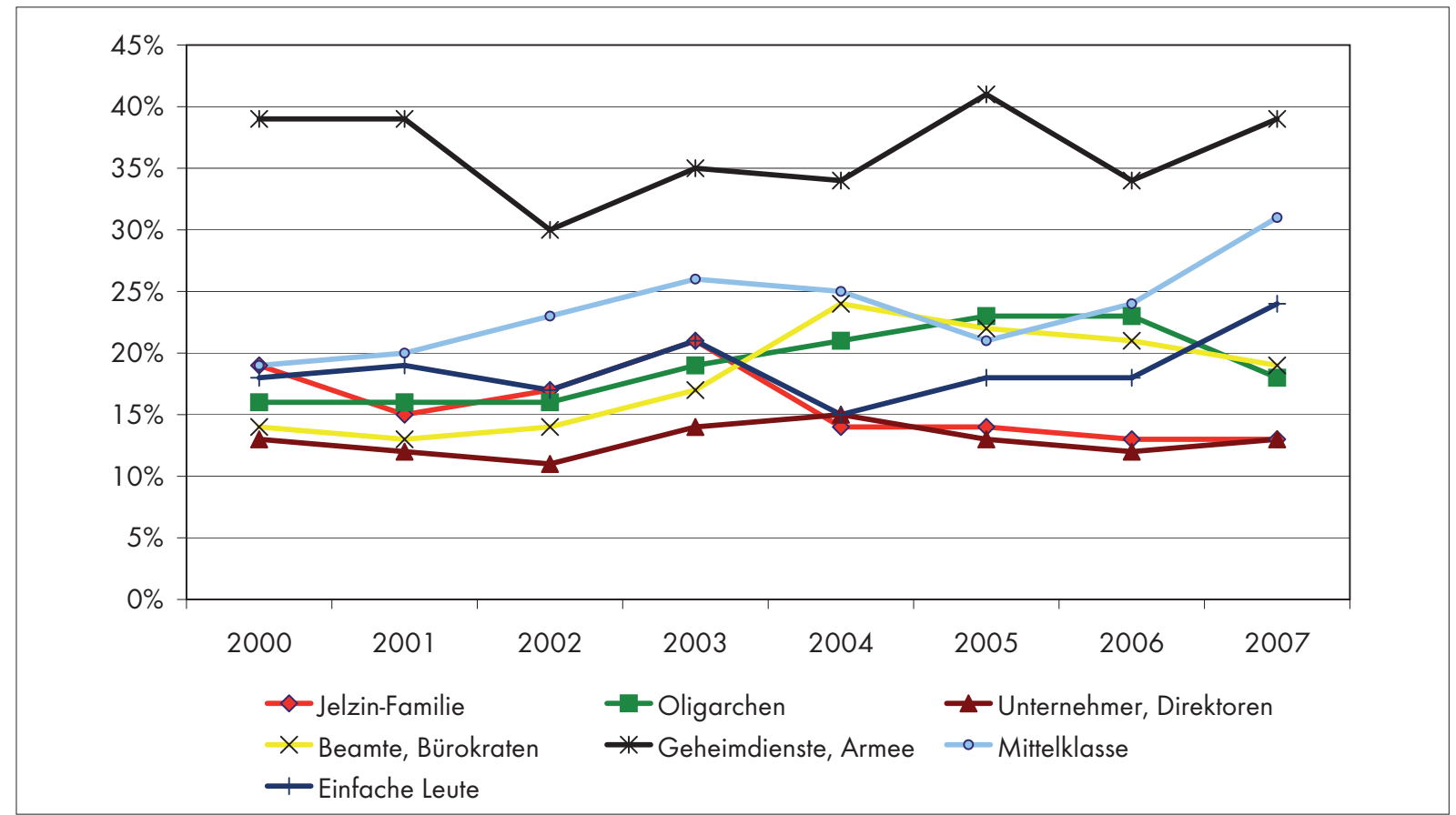

Quelle: Umfragen des Levadazentrums aus dem August 2007 http:// w w w.leva da .ru./ p ress/ 2007091202 .html 


\section{Chronik}

\section{Vom 12. bis zum 27. September 2007}

\begin{tabular}{|c|c|}
\hline 12.9 .2007 & $\begin{array}{l}\text { Präsident Wladimir Putin nimmt das Rücktrittsgesuch von Ministerpräsident Michail Fradkow an und no- } \\
\text { miniert Viktor Subkow, den Chef der Finanzaufsicht, als Nachfolger. }\end{array}$ \\
\hline 12.9.2007 & $\begin{array}{l}\text { In Naltschik, der Hauptstadt der Republik Kabardino-Balkarien, wird ein Bombenanschlag auf ein Polizei- } \\
\text { fahrzeug verübt. Menschen kommen nicht zu Schaden. }\end{array}$ \\
\hline 13.9.2007 & $\begin{array}{l}\text { Admiral Wladimir Wysozkij, bisher Befehlshaber der Nordmeerflotte, wird zum Oberbefehlshaber der See- } \\
\text { kriegsflotte ernannt. Er folgt Admiral Vladimir Masorin, der mit } 60 \text { Jahren die Altersgrenze erreicht hat. }\end{array}$ \\
\hline 13.9.2007 & $\begin{array}{l}\text { In Chasania (Republik Kabardino-Balkarien) wird ein Fahrzeug der Sicherheitskräfte durch eine Bombe be- } \\
\text { schädigt. Bei der folgenden Razzia kommt es zu einem Feuergefecht, bei dem ein Untergrundkämpfer getö- } \\
\text { tet wird. Drei Polizisten werden verwundet. }\end{array}$ \\
\hline 13.9.2007 & $\begin{array}{l}\text { Boris Semzow, Stellvertretender Herausgeber der Tageszeitung "Nesawisimaja gaseta«, wird wegen Erpres- } \\
\text { sung festgenommen. }\end{array}$ \\
\hline 13.-14.9.2007 & In Nazran (Inguschetien) wird das Polizeihauptquartier mit Granatwerfern beschossen. \\
\hline 14.9.2007 & Die Staatsduma bestätigt Viktor Subkow mit 381 gegen 47 Stimmen als Ministerpräsidenten. \\
\hline 14.9.2007 & $\begin{array}{l}\text { Die Zeitung "Komsomolskaja prawda» teilt mit, dass die Moskauer Behörden Schamil Burajew, früher Ver- } \\
\text { waltungschef im Rayon Atschkhoj-Martan (Tschetschenien) im Zusammenhang mit der Ermordung der } \\
\text { Journalistin Anna Politkowskaja festgenommen haben. }\end{array}$ \\
\hline 16.9.2007 & In Moskau wird der Sohn eines iranischen Diplomaten von Unbekannten erstochen. \\
\hline 17.9.2007 & $\begin{array}{l}\text { Der polnische Präsident Lech Kaczyński legt anlässlich des Jahrestages des sowjetischen Einmarsches in Po- } \\
\text { len am 16.9.1939 in Katyn, } 20 \mathrm{~km} \text { von Smolensk, an der Gedenkstätte der ermordeten polnischen Offizie- } \\
\text { re einen Kranz nieder. }\end{array}$ \\
\hline 17.9.2007 & $\begin{array}{l}\text { Der deutsche Energiekonzern E.on teilt mit, dass er für 4,1 Mrd. Euro den russischen Strom-Erzeugers } \\
\text { OGK-4 erworben hat. }\end{array}$ \\
\hline 17.9.2007 & $\begin{array}{l}\text { In Gazi-Yurt (Bezirk Nasran, Inguschetien) wird der Oberstleutnant des Inlandsgeheimdienstes Alichan Ka- } \\
\text { limatow von Unbekannten erschossen. }\end{array}$ \\
\hline 18.9.2007 & Im russischen Internet .ru ist die Millionste Adresse registriert worden. \\
\hline 18.9.2007 & $\begin{array}{l}\text { In Nowyj Sulak (Dagestan) wird der Untergrundführer Rappani Chalilow im Laufe einer Spezialoperati- } \\
\text { on getötet. }\end{array}$ \\
\hline 18.9.2007 & $\begin{array}{l}\text { Verteidigungsminister Anatolij Serdjukow kündigt seinen Rücktritt an, da die enge Verwandschaft - er ist } \\
\text { Schwiegersohn des neuen Ministerpräsidenten Viktor Subkow - mit dem Amt nicht vereinbar sei. Dieser } \\
\text { Rücktritt wird aber einige Tage später im Zuge der Regierungsbildung nicht angenommen, so dass Serdju- } \\
\text { kow im Amt bleibt. }\end{array}$ \\
\hline 18.9.2007 & $\begin{array}{l}\text { Der französische Außenminister Bernard Kouchner führt in Moskau Gespräche mit seinem russischen Amts- } \\
\text { kollegen Sergej Lawrow. U.a. geht es um die Frage der iranischen Nuklearpolitik. }\end{array}$ \\
\hline 18.9.2007 & $\begin{array}{l}\text { Der Soziologie und Philosoph Boris Gruschin stirbt nach langer Krankheit im Alter von } 78 \text { Jahren. Gruschin } \\
\text { hat seit den 1960er Jahren in der Sowjetunion Meinungsumfragen durchgeführt und war einer der Gründer } \\
\text { des Meinungsforschungsinstituts VCIOM. }\end{array}$ \\
\hline 19.9.2007 & $\begin{array}{l}\text { Jose Manuel Barroso, der Präsident der Europäischen Kommission, kündigt eine Gesetzgebung zur Libera- } \\
\text { lisierung des europäischen Energiemarktes an. Die Vorlage sieht u.a. vor, ausländischen Energiekonzernen } \\
\text { (wie z.B. Gazprom) den Eintritt in den europäischen Binnenmarkt zu verweigern, wenn deren Mutterlän- } \\
\text { der ihre Märkte nicht öffnen. }\end{array}$ \\
\hline 19.9.2007 & $\begin{array}{l}\text { Bei der Abstimmung im UN-Sicherheitsrat über die Verlängerung des Mandats für die ISAF-Truppen Af- } \\
\text { ghanistan enthält sich Russland der Stimme. }\end{array}$ \\
\hline
\end{tabular}




\begin{tabular}{|c|c|}
\hline 19.9.2007 & $\begin{array}{l}\text { 800-900 Einwohner der Siedlung Surchachi, im Südosten von Nasran (Inguschetien) demonstrieren für } \\
\text { die Freilassung von zwei jungen Männern, die von Unbekannten entführt worden sind. Es kommt zu Zu- } \\
\text { sammenstößen mit Sicherheitskräften. Die Demonstration endet, als bekannt wird, dass die Gesuchten frei- } \\
\text { gelassen wurden. }\end{array}$ \\
\hline 20.9 .2007 & $\begin{array}{l}\text { Viktor Scherschunow, der Gouverneur von Kostroma, und sein Fahrer werden bei einem Autounfall getö- } \\
\text { tet. }\end{array}$ \\
\hline 20.9 .2007 & $\begin{array}{l}\text { In Zentrum von Machatschkala umstellen Sicherheitskräfte einen Wohnblock, in dem sich zwei Untergrund- } \\
\text { kämpfer verborgen halten. Im Verlauf der Operation werden zwei Wohnhäuser zerstört, zwei weitere beschä- } \\
\text { digt. Die beiden Guerillakämpfer und ein Angehöriger der Sicherheitskräfte werden getötet. }\end{array}$ \\
\hline 20.9 .2007 & $\begin{array}{l}\text { Drei Angehörige des Rechnungshofes werden unter dem Verdacht festgenommen, Bestechungsgelder in Höhe } \\
\text { von einer Millionen Euro erpresst zu haben. }\end{array}$ \\
\hline 21.9.2007 & $\begin{array}{l}\text { Der irakische Außenminister Hoshyar Zebari besucht Moskau und lädt russische Unternehmen ein, sich in } \\
\text { der irakischen Gas- und Ölindustrie zu engagieren. }\end{array}$ \\
\hline 21.9 .2007 & $\begin{array}{l}\text { In Ali-jurt, südöstlich von Nasran (Inguschetien), kommt es zu einem Feuergefecht zwischen Untegrund- } \\
\text { kämpfern und Sicherheitskräften. Ein Guerilla wird getötet, mehrere Polizisten verletzt. }\end{array}$ \\
\hline 23.9.2007 & $\begin{array}{l}\text { Der ehemalige Bundeskanzler Gerhard Schröder und der frühere französische Präsident Jacques Chirac tref- } \\
\text { fen zu einem Privatbesuch bei Putin in Sotschi ein. }\end{array}$ \\
\hline 24.9.2007 & $\begin{array}{l}\text { Präsident Putin stellt das neue Kabinett vor, das nur auf drei Positionen verändert ist. Dmitrij Kosak über- } \\
\text { nimmt das Ministerium für Regionalentwicklung, Tatjana Golikowa löst Michail Surabow im Gesund- } \\
\text { heits- und Sozialressort ab und Elvira Nabiullina ersetzt German Gref. Finanzminister Kudrin wird unter } \\
\text { Beibehaltung seines Amtes zum stellvertretenden Ministerpräsident befördert. Das Rücktrittsangebot von } \\
\text { Verteidigungsminister Serdjukow wird nicht angenommen. }\end{array}$ \\
\hline 25.9.2007 & $\begin{array}{l}\text { Putin verlagert per Dekret die Verfügung über den Investitionsfonds aus vom Ministerium für Wirtschafts- } \\
\text { entwicklung und Handel zum Ministerium für Regionalentwicklung. Der Fonds verfügt } 2007 \text { über Mittel } \\
\text { in Höhe von 4,4 Mrd. US\$ zur Finanzierung regionaler Investitionsprojekte. }\end{array}$ \\
\hline 25.9.2007 & $\begin{array}{l}\text { In einem Moskauer Bezirksgericht beginnt der Prozess gegen den Politologen Andrej Piontkowskij, dem vor- } \\
\text { geworfen wird, in seinem neuen Buch »Ungeliebtes Land« Extremismus geschürt zu haben. }\end{array}$ \\
\hline 25.9.2007 & $\begin{array}{l}\text { Putin entlässt den Leiter der Abteilung für Aufrechterhaltung der öffentlichen Ordnung im Innenministe- } \\
\text { rium, Nikolaj Perschutkin. Zeitgleich werden die Leiter der entsprechenden Abteilungen in St. Petersburg } \\
\text { und im Gebiet Leningrad entlassen. }\end{array}$ \\
\hline 25.9.2007 & $\begin{array}{l}\text { Die Föderale Steuerbehörde kündigt an, dass sie eine Spezialinspektion zur Steuerprüfung bei "größeren } \\
\text { Steuerzahlern«schaffen will. }\end{array}$ \\
\hline 26.9.2007 & $\begin{array}{l}\text { Im Rahmen seiner Gespräche mit den Fraktionsvorsitzenden in der Duma empfängt Putin Sergej Baburin, } \\
\text { den Vorsitzenden der Partei »Volksunion« zu einem Gespräch. Nach dem Gespräch kündigt dieser für den } \\
\text { 4. 11. den "Russischen Marsch» an. Dabei handelt es sich um eine Demonstration rechtsradikalter Grup- } \\
\text { pierungen. }\end{array}$ \\
\hline 26.9 .2007 & $\begin{array}{l}\text { Auf seiner ersten Reise im neuen Amt besucht Ministerpräsident Subkow das Gebiet Pensa und setzt sich für } \\
\text { die sozialen Belange der Landbevölkerung ein. }\end{array}$ \\
\hline 27.9.2007 & $\begin{array}{l}\text { Die Zeitung "Vedomosti« berichtet, dass Putin der Partei „Einiges Russland« gestattet, in der Wahlkampa- } \\
\text { gne sein Porträt einzusetzen. }\end{array}$ \\
\hline
\end{tabular}

Die Russlandanalysen werden mit Unterstützung durch die Otto-Wolff-Stiftung gemeinsam von der Forschungsstelle Osteuropa an der Universität Bremen und der Deutschen Gesellschaft für Osteuropakunde herausgegeben.

\author{
Die Meinungen, die in den Russlandanalysen geäußert werden, geben ausschließlich die Auffassung der Autoren wieder. \\ Abdruck und sonstige publizistische Nutzung sind nach Rücksprache mit der Redaktion gestattet. \\ Redaktion und technische Gestaltung: Matthias Neumann, Heiko Pleines, Hans-Henning Schröder \\ Russlandanalysen-Layout: Cengiz Kibaroglu \\ ISSN 1613-3390 (c) 2007 by Forschungsstelle Osteuropa, Bremen \\ Forschungsstelle Osteuropa • Publikationsreferat • Klagenfurter Str. 3 • 28359 Bremen • Telefon: +49 421-218-7891 • Telefax: +49 421-218-3269 \\ e-mail: publikationsrefera@@osteuropa.uni-bremen.de・Internet-Adresse: www.russlandanalysen.de
}




\section{Lesehinweis}

\section{Kostenlose E-Mail-Dienste der Forschungsstelle Osteuropa}

\section{Russlandanalysen}

Die "Russlandanalysen« bieten wöchentlich eine Kurzanalyse zu einem aktuellen Thema, ergänzt um Grafiken und Tabellen. Zusätzlich gibt es eine Wochenchronik aktueller politischer Ereignisse.

Abonnement unter: fsopr@uni-bremen.de

\section{Russian Analytical Digest}

Der Russian Analytical Digest bietet zweimal monatlich englischsprachige Kurzanalysen sowie illustrierende Daten zu einem aktuellen Thema.

Abonnement unter: http:// w w w.res.ethz.ch/ analysis/ rad/

\section{kultura. Russland-Kulturanalysen}

Die Russland-Kulturanalysen diskutieren in kurzen, wissenschaftlich fundierten, doch publizistisch-aufbereiteten Beiträgen signifikante Entwicklungen der Kultursphäre Russlands. Jede Ausgabe enthält zwei Analysen und einige Kurztexte bzw. Illustrationen. Erscheinungsweise: monatlich, in je einer deutschen und englischen Ausgabe.

Abonnement unter: fsopr@uni-bremen.de

\section{Ukraine-Analysen}

Die Ukraine-Analysen bieten zweimal monatliche eine Kurzanalyse zu einem aktuellen Thema aus Politik, Wirtschaft oder Kultur, ergänzt um Grafiken und Tabellen. Zusätzlich gibt es eine Chronik aktueller Ereignisse.

Abonnement unter: fsopr@uni-bremen.de

\section{Polen-Analysen}

Die Polen-Analysen bieten zweimal monatliche eine Kurzanalyse zu einem aktuellen Thema aus Politik, Wirtschaft oder Kultur, ergänzt um Grafiken und Tabellen. Zusätzlich gibt es eine Chronik aktueller Ereignisse.

Abonnement unter: http:// w w w.polen-analysen.de

\section{Bibliographische Dienste}

Die vierteljährlich erscheinenden Bibliographien informieren über englisch- und deutschsprachige Neuerscheinungen zu Polen, Russland, Tschechischer und Slowakischer Republik sowie zur Ukraine. Erfasst werden jeweils die Themenbereiche Politik, Außenpolitik, Wirtschaft und Soziales.

Abonnement unter: fsopr@uni-bremen.de 